Discovery of Neolignan Glycosides with Acetylcolinesterase Inhibitory Activity from Huangjinya Green Tea Guided by UPLC-MS² data and GNPS Molecular Networking

Hao-Yue Wu,${ }^{\dagger}$ Jia-Ping Ke,${ }^{\dagger}$ Wei Wang, ${ }^{\dagger}$ Ya-Shuai Kong, ${ }^{\dagger}$ Peng Zhang, ${ }^{\dagger}$ Tie-Jun Ling, ${ }^{\dagger}$ Guan-Hu Bao ${ }^{\dagger}, *$

Natural Products Laboratory, State Key Laboratory of Tea Plant Biology and Utilization, Anhui Agricultural University, Hefei, Anhui Province 230036, China

*Corresponding author. Phone: +86-551-65786401. Fax: +86-551-65786765; E-mail: c (G.-H. Bao). 


\section{List of supplementary materials}

Figure S1. HPLC preparation of compound 1 and 2.

Figure S2. HPLC pure test of compound $\mathbf{1}$ and $\mathbf{2}$ with UV detection at the wavelength $280 \mathrm{~nm}$.

Figure S3. UV of compound 1.

Figure S4. UV of compound 2.

Figure S5. ${ }^{1} \mathrm{H}$ NMR data of compound 1 in DMSO- $d_{6}$.

Figure S6. ${ }^{13} \mathrm{C}$ NMR data of compound 1 in DMSO- $d_{6}$.

Figure S7. COSY data of compound 1 in DMSO- $d_{6}$.

Figure S8. HSQC data of compound 1 in DMSO- $d_{6}$.

Figure S9. HMBC data of compound 1 in DMSO- $d_{6}$.

Figure S10. ROESY data of compound 1 in DMSO- $d_{6}$.

Figure S11. ${ }^{1} \mathrm{H}$ NMR data of compound 2 in DMSO- $d_{6}$.

Figure S12. ${ }^{13} \mathrm{C}$ NMR data of compound 2 in DMSO- $d_{6}$.

Figure S13. COSY data of compound 2 in DMSO- $d_{6}$.

Figure S14. HSQC data of compound 2 in DMSO- $d_{6}$.

Figure S15. HMBC data of compound 2 in DMSO- $d_{6}$.

Figure S16. NOESY data of compound 2 in DMSO- $d_{6}$.

Figure S17. HR-ESI-MS spectrum of 1.

Figure S18. HR-ESI-MS spectrum of 2.

Figure S19. HR-ESI-MS spectrum of $\mathbf{3}$.

Figure S20. HR-ESI-MS spectrum of 4. 
Figure S21. HR-ESI-MS spectrum of 5.

Figure S22. HR-ESI-MS spectrum of 6.

Figure S23. HR-ESI-MS spectrum of 7.

Figure S24. HR-ESI-MS spectrum of 8.

Figure S25. HR-ESI-MS spectrum of 9.

Figure S26. HR-ESI-MS spectrum of $\mathbf{1 0 .}$

Figure S27. HR-ESI-MS spectrum of $\mathbf{1 1 .}$

Figure S28. HR-ESI-MS spectrum of $\mathbf{1 2}$.

Figure S29. HR-ESI-MS spectrum of $\mathbf{1 3 .}$

Figure S30. HR-ESI-MS spectrum of $\mathbf{1 4 .}$

Figure S31. HR-ESI-MS spectrum of $\mathbf{1 5 .}$

Figure S32. HR-ESI-MS spectrum of $\mathbf{1 6 .}$

Figure S33. Circular dichroism spectra of compound 1.

Figure S34. Circular dichroism spectra of compound 2.

Figure S35. Purity checks of $\mathbf{1}$ and $\mathbf{2}$ by HPLC with a chiral column.

Figure S36. ${ }^{1} \mathrm{H}$ NMR data of compound $1 \mathrm{a}$ in $\mathrm{CDCl}_{3}-d$.

Figure S37. ${ }^{1} \mathrm{H}$ NMR data of compound 2a in $\mathrm{CDCl}_{3}-d$.

Figure S38. The IR spectrum of compound $\mathbf{1}$.

Figure S39. The IR spectrum of compound 2.

Figure S40. GC-MS identification of the glucose (Glc) moiety of $\mathbf{1 .}$

Figure S41. Molecular networking of flavonols in Huangjinya green tea.

Table S1. HPLC preparation method for compound 1 and 2 . 
Table S2. The inhibitory activities of the compounds against AChE in vitro . 


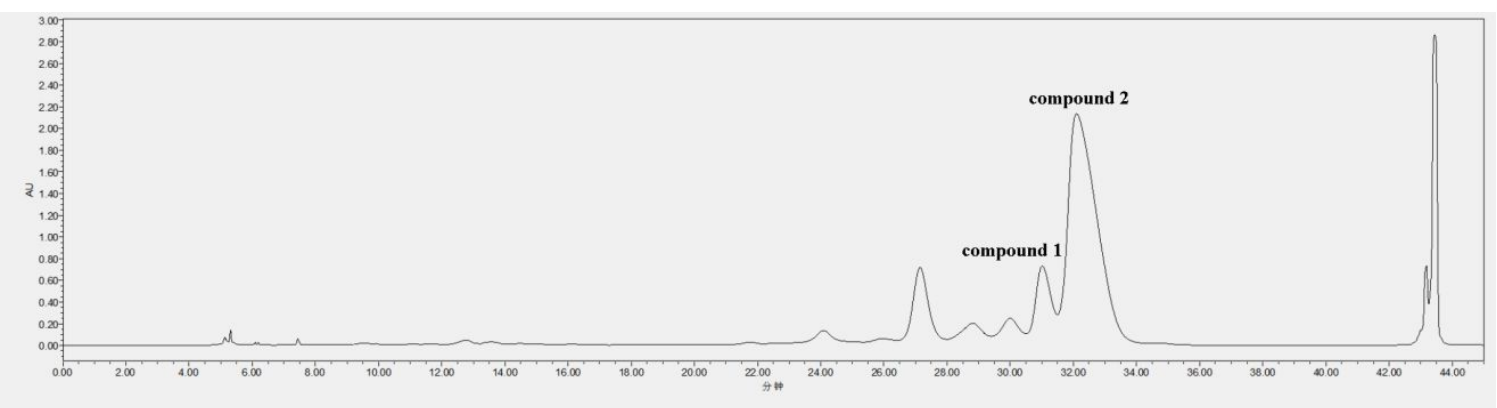

Figure Supporting 1. HPLC preparation of compound $\mathbf{1}$ and $\mathbf{2}$ with UV detection at the wavelength $280 \mathrm{~nm}$.
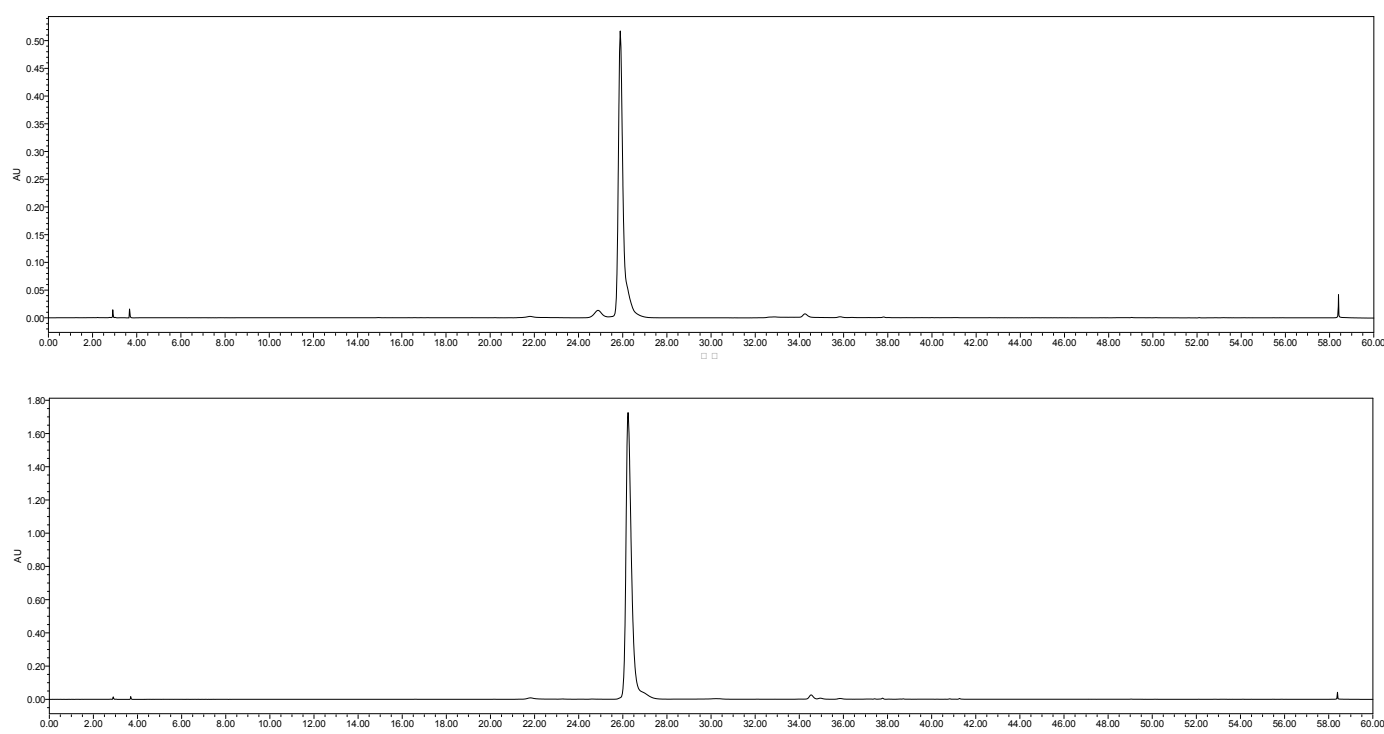

Figure Supporting 2. HPLC pure test of compound $\mathbf{1}$ and $\mathbf{2}$ with UV detection at the wavelength $280 \mathrm{~nm}$. 


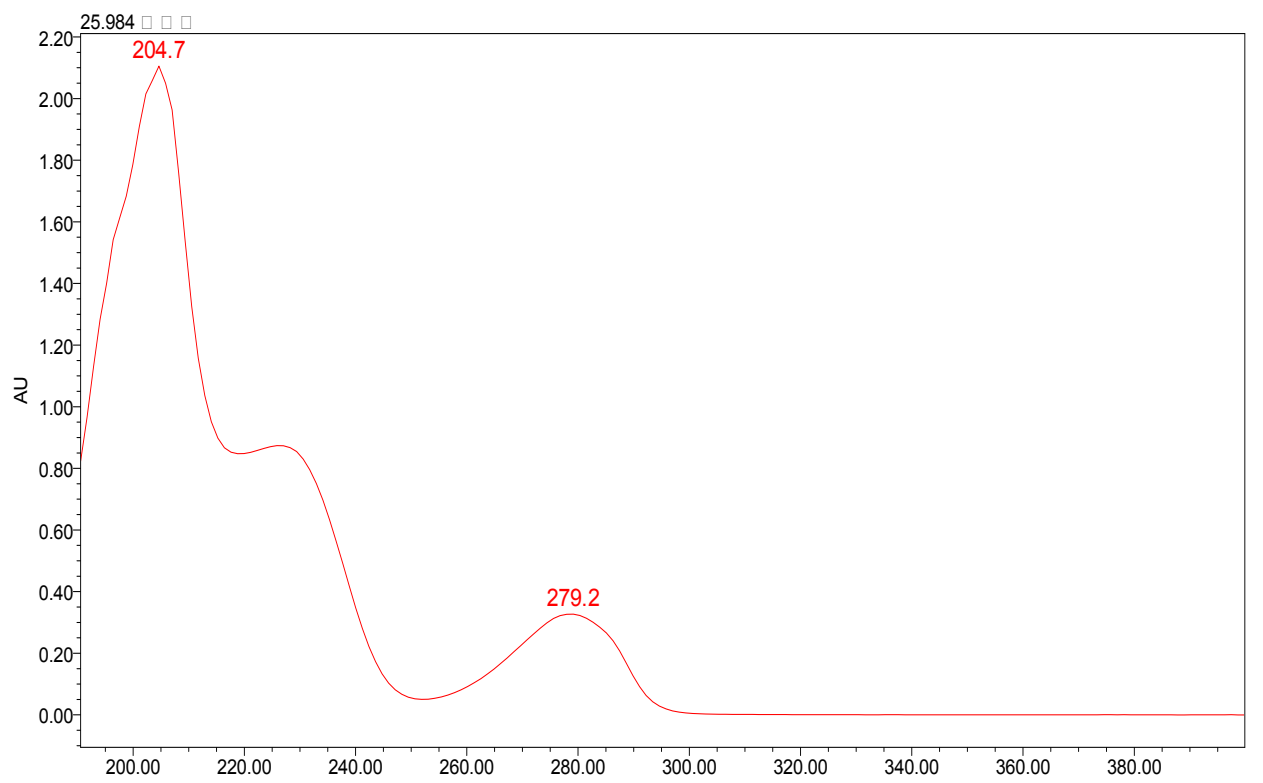

Figure Supporting 3. UV of compound 1.

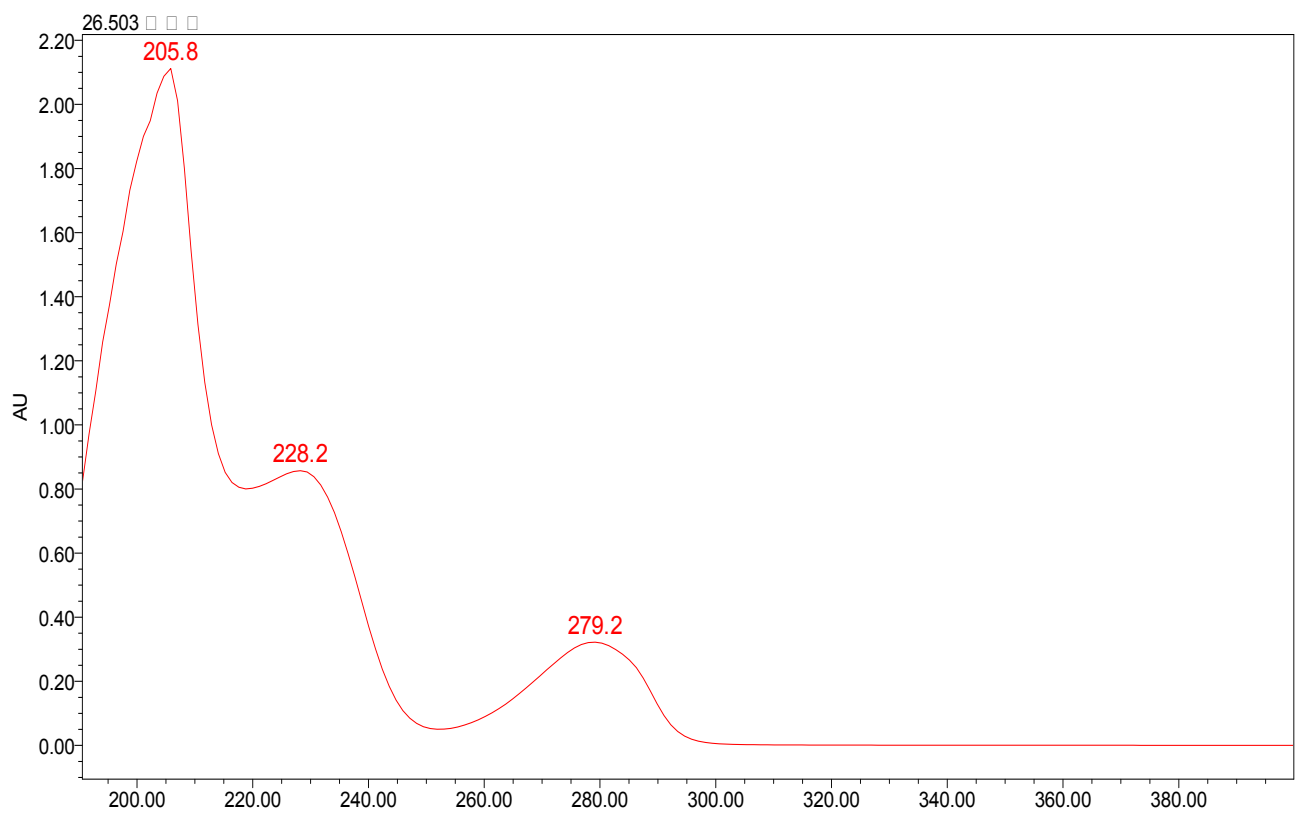

Figure Supporting 4. UV of compound 2. 


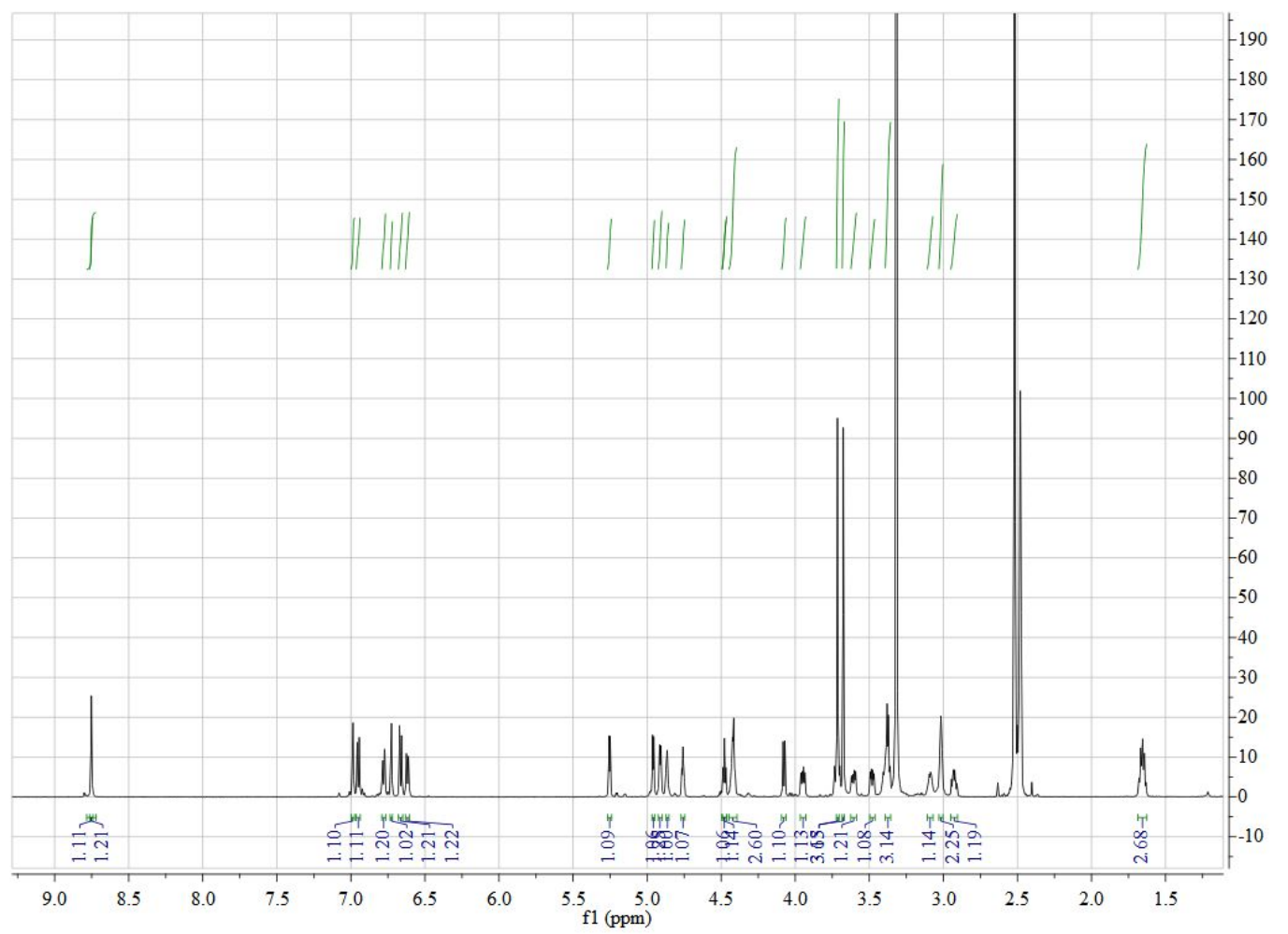

Figure Supporting 5. ${ }^{1} \mathrm{H}$ NMR data of compound 1 in DMSO- $d_{6}$.

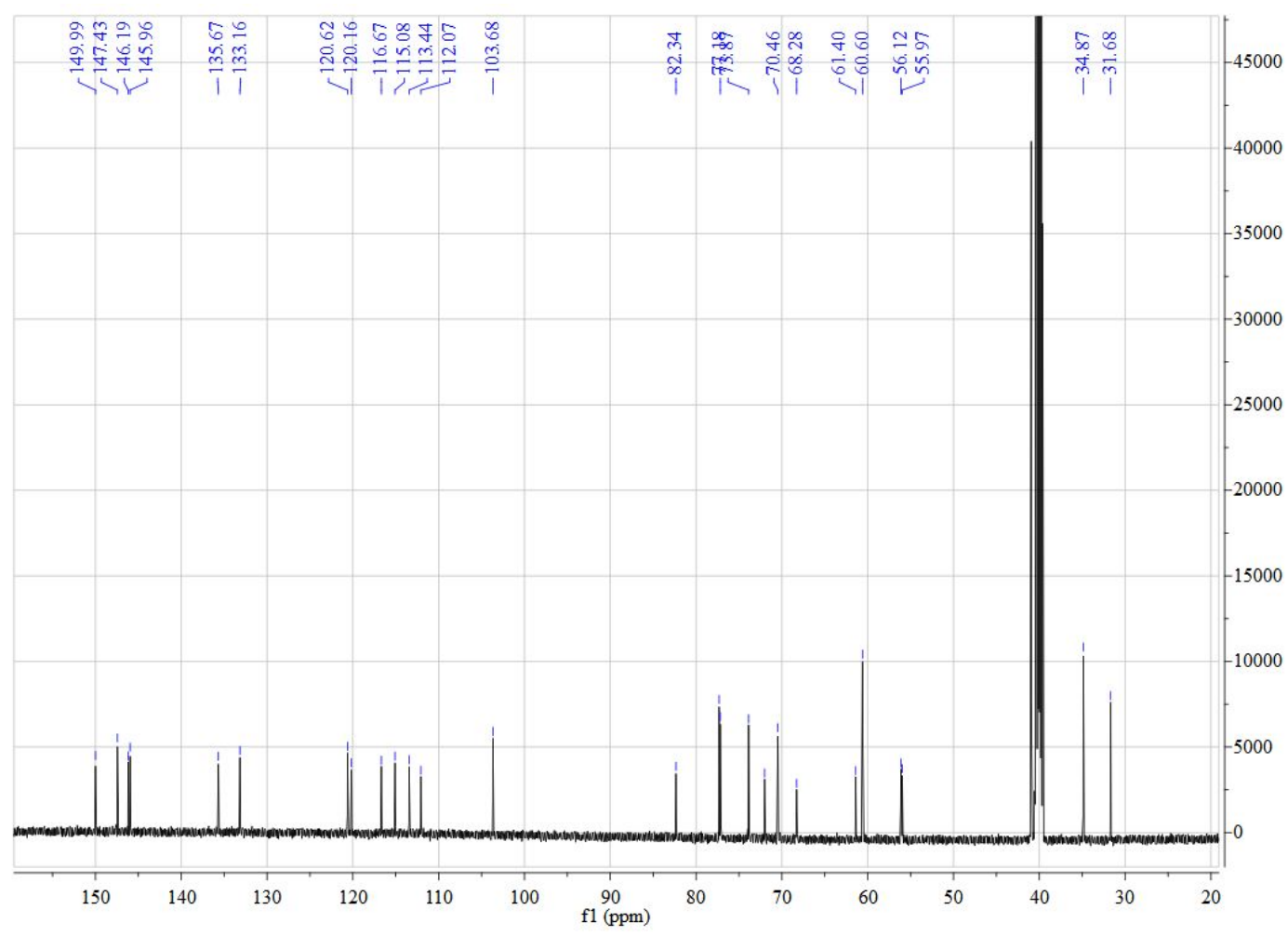

Figure Supporting 6. ${ }^{13} \mathrm{C}$ NMR data of compound 1 in DMSO- $d_{6}$. 


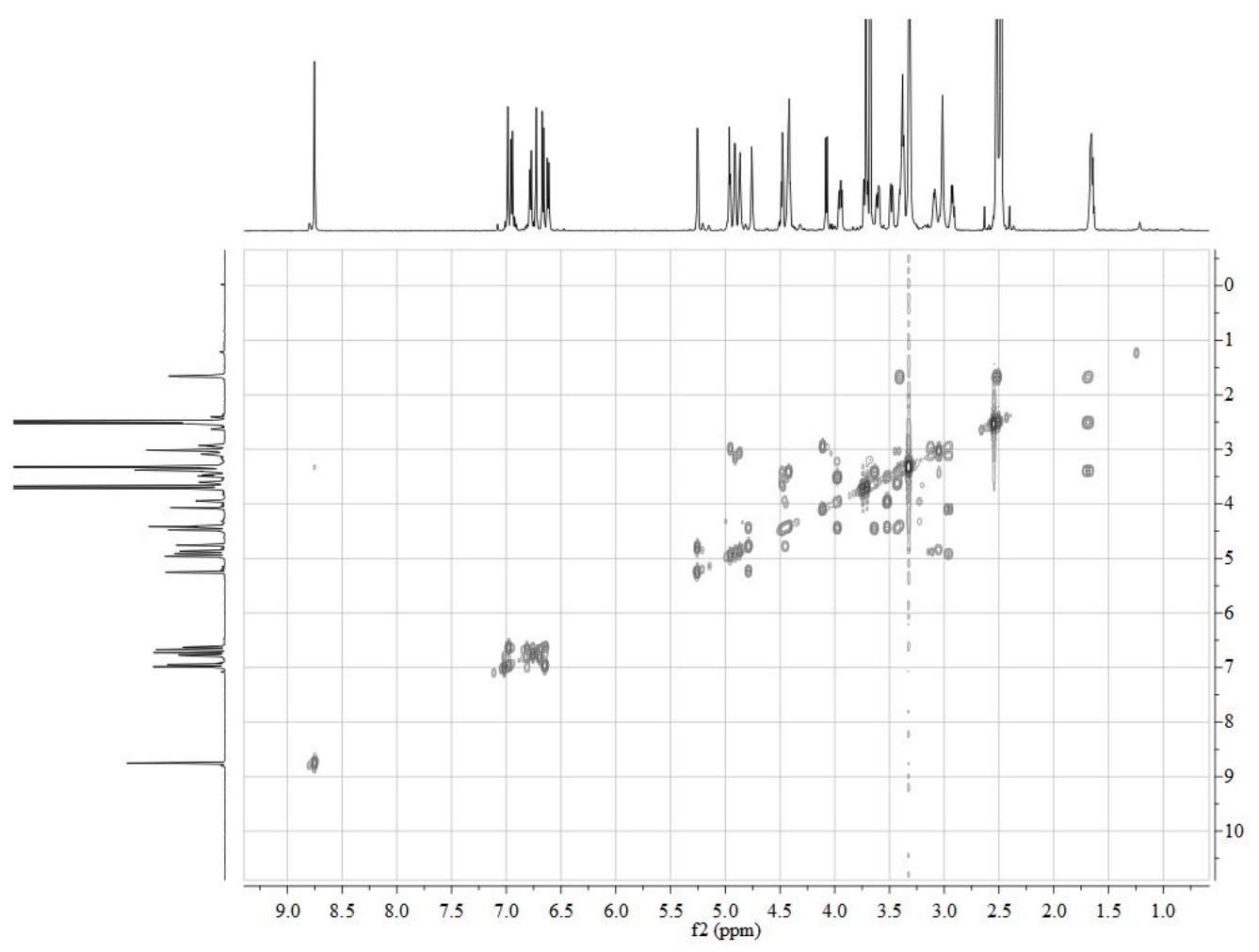

Figure Supporting 7. COSY data of compound 1 in DMSO- $d_{6}$.

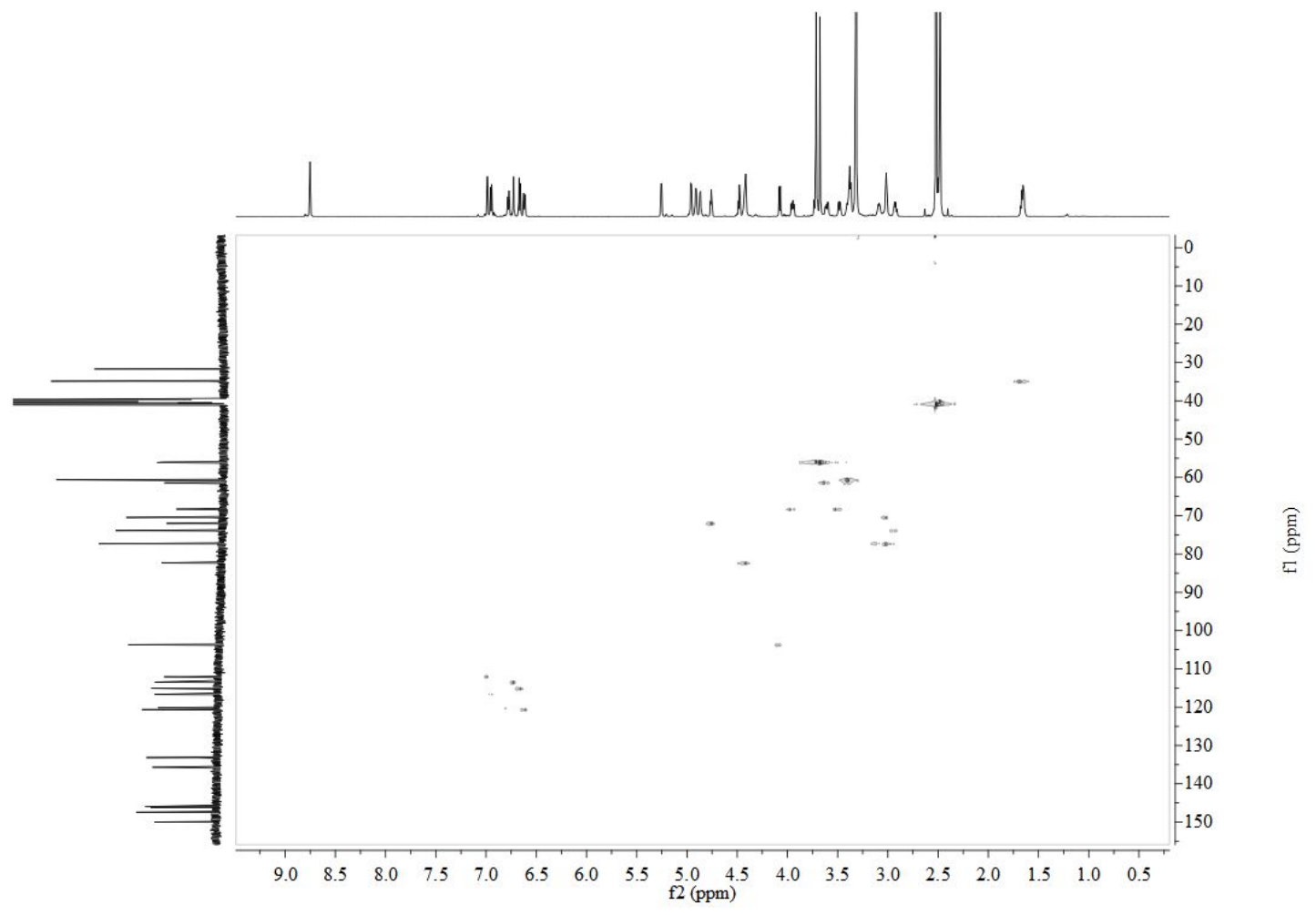

Figure Supporting 8. HSQC data of compound 1 in DMSO- $d_{6}$. 


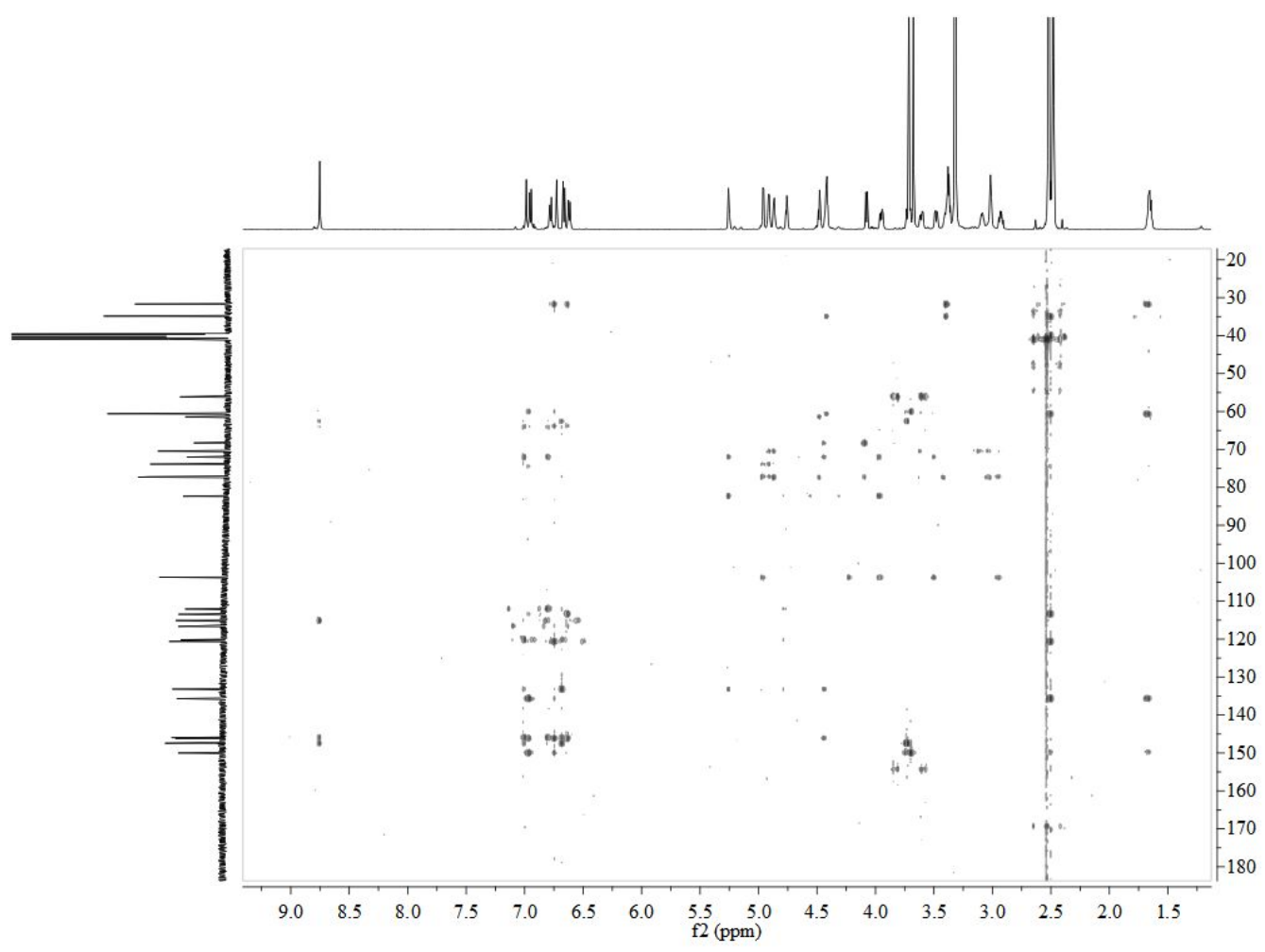

Figure Supporting 9. HMBC data of compound 1 in DMSO- $d_{6}$.

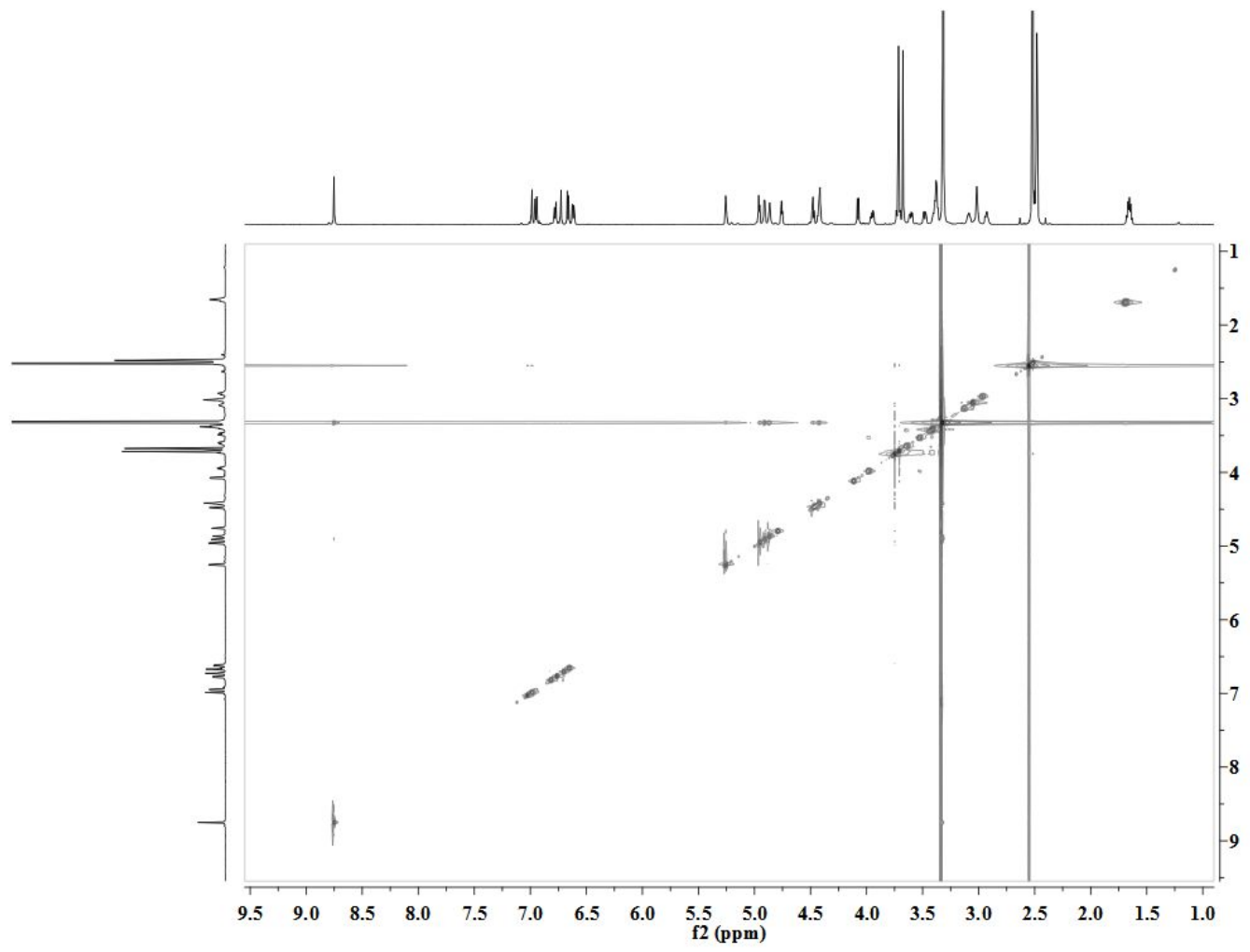

Figure Supporting 10. ROESY data of compound 1 in DMSO- $d_{6}$. 


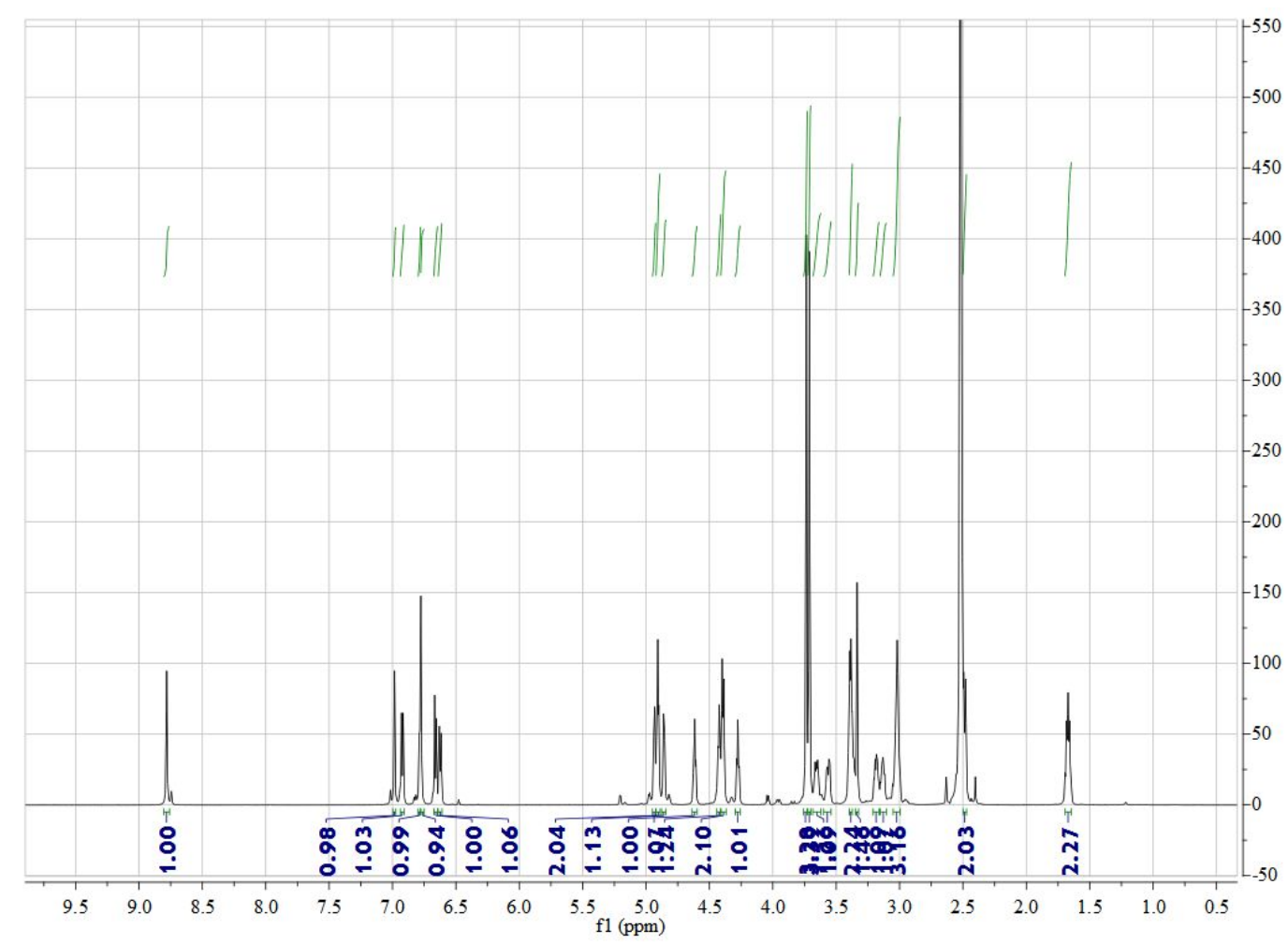

Figure Supporting 11. ${ }^{1} \mathrm{H}$ NMR data of compound 2 in DMSO- $d_{6}$.

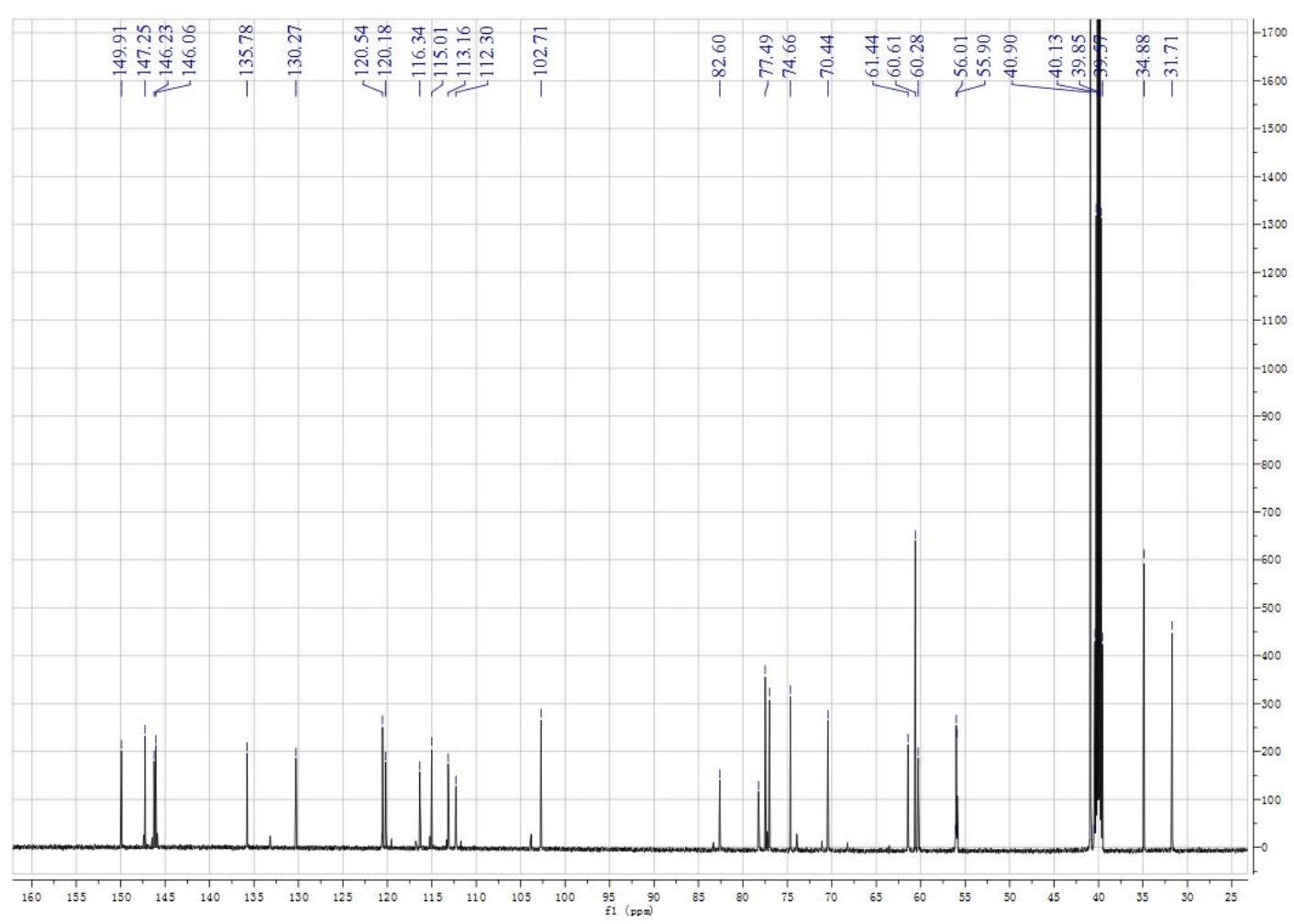

Figure Supporting 12. ${ }^{13} \mathrm{C}$ NMR data of compound 2 in DMSO- $d_{6}$. 


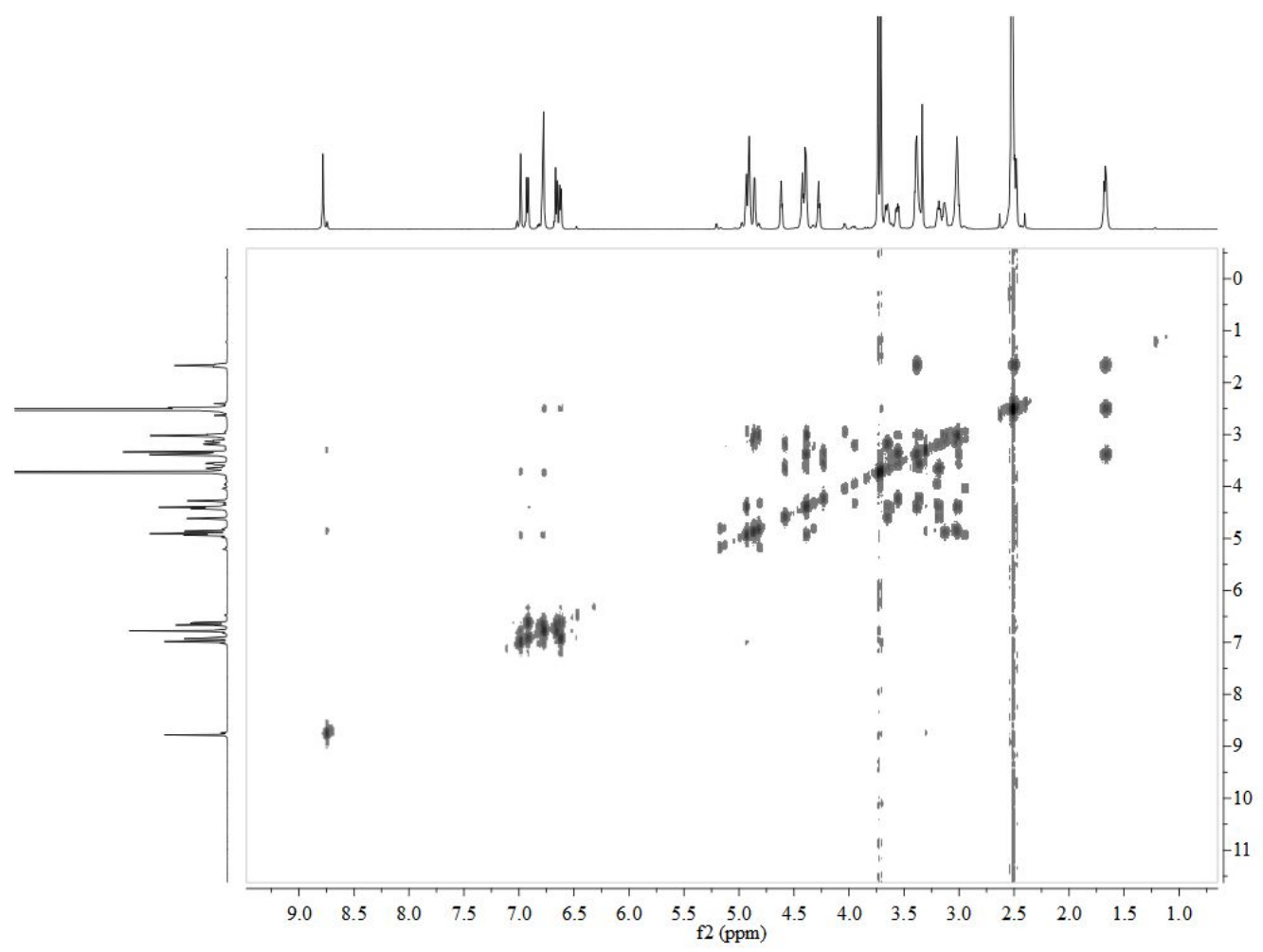

Figure Supporting 13. COSY data of compound 2 in DMSO- $d_{6}$.

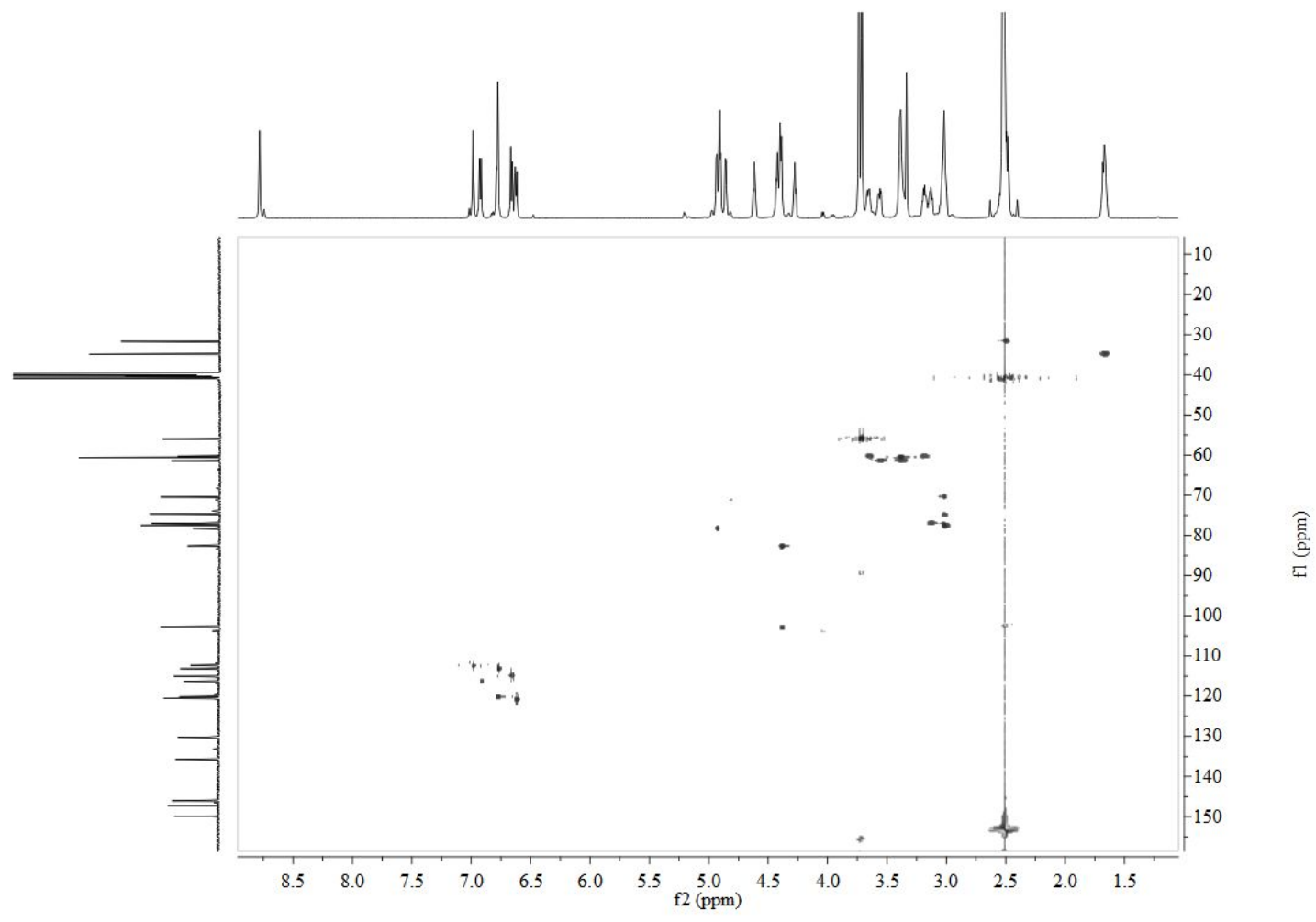

Figure Supporting 14. HSQC data of compound 2 in DMSO- $d_{6}$. 


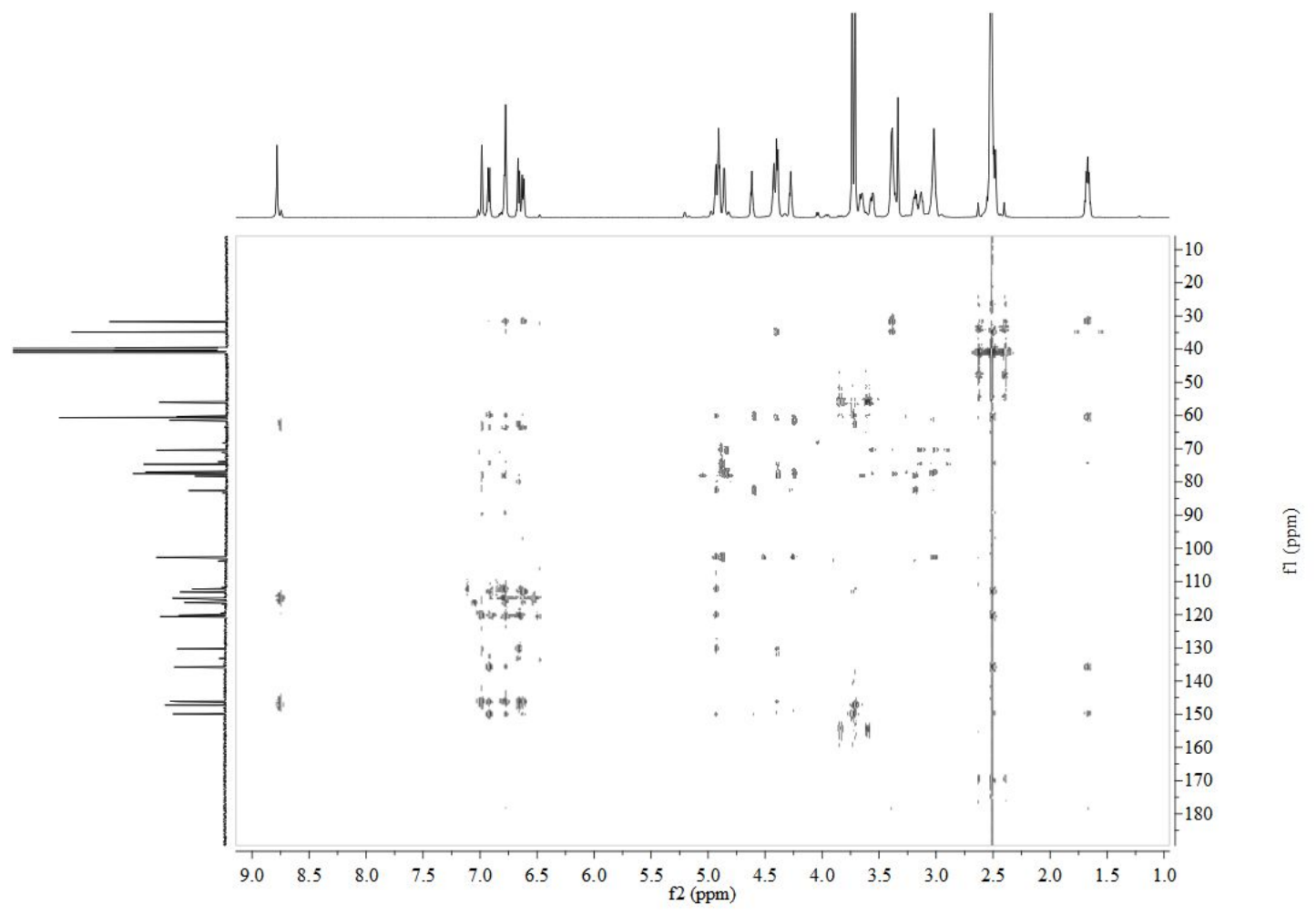

Figure Supporting 15. HMBC data of compound 2 in DMSO- $d_{6}$.

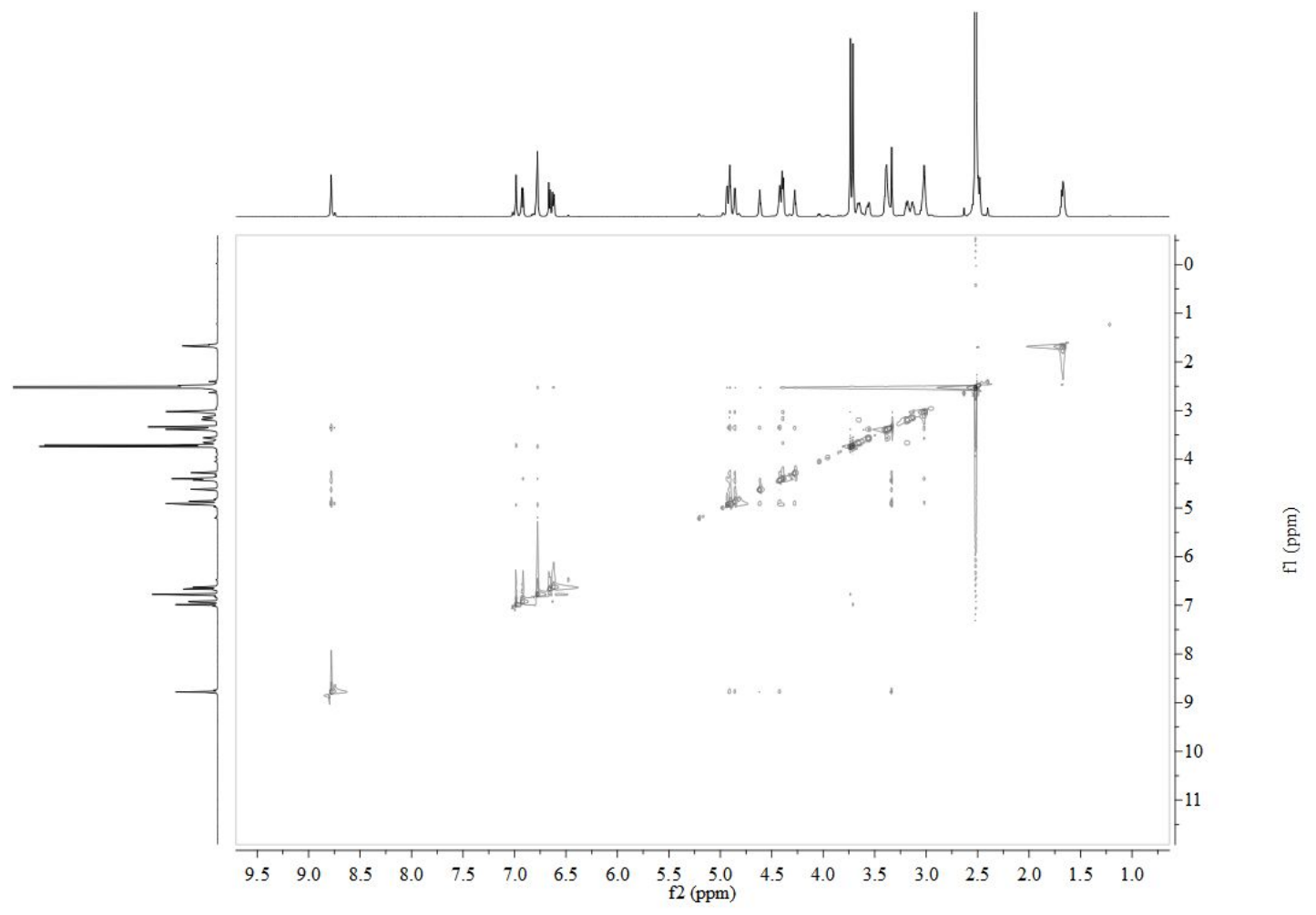

Figure Supporting 16. NOESY data of compound 2 in DMSO- $d_{6}$. 


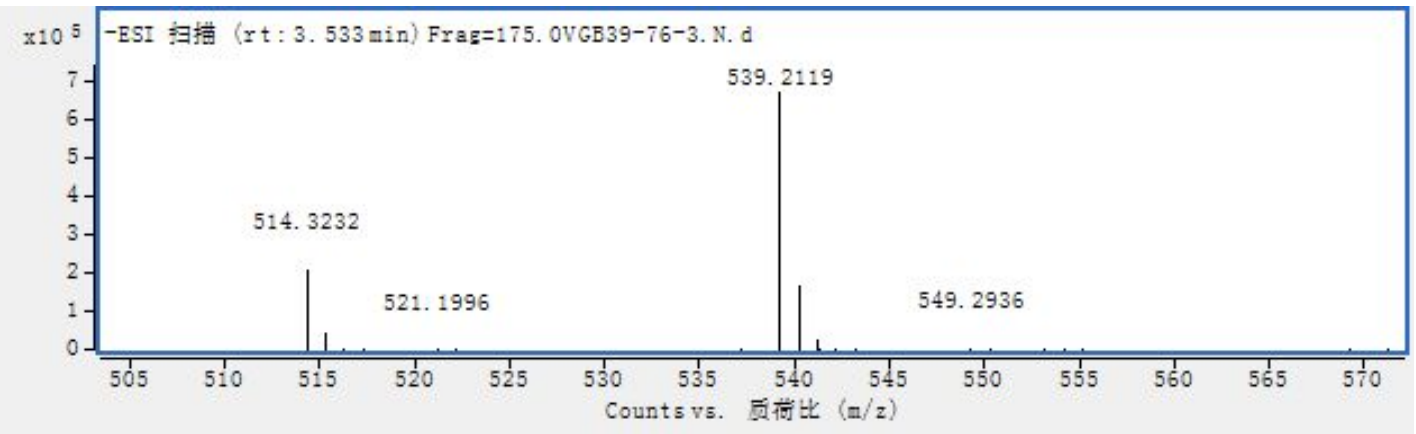

Figure Supporting 17. HR-ESI-MS spectrum of 1.

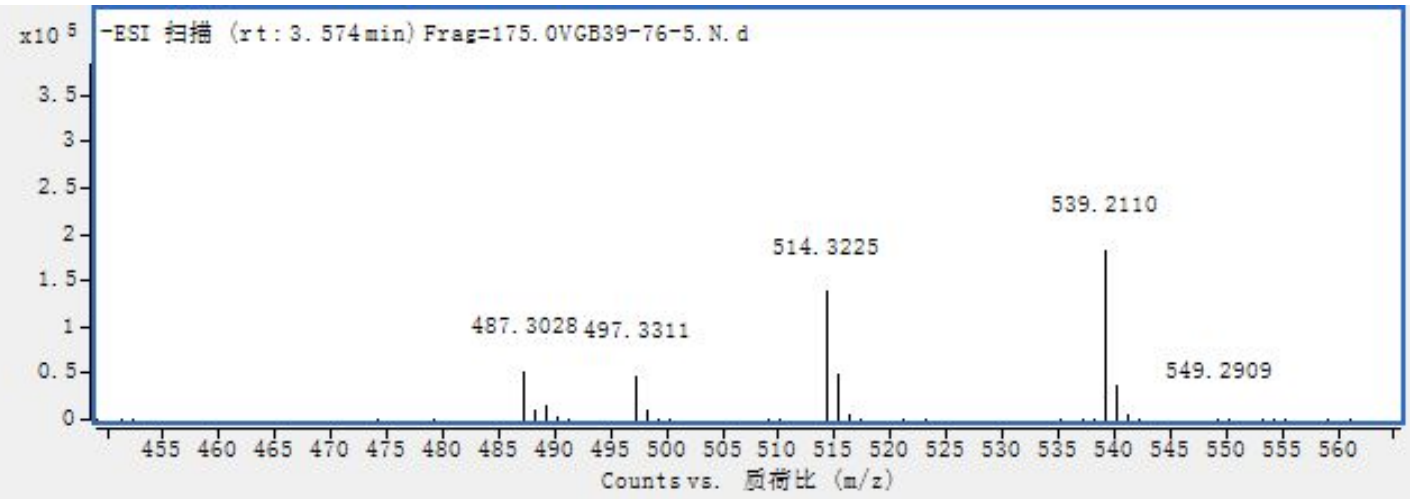

Figure Supporting 18. HR-ESI-MS spectrum of 2.

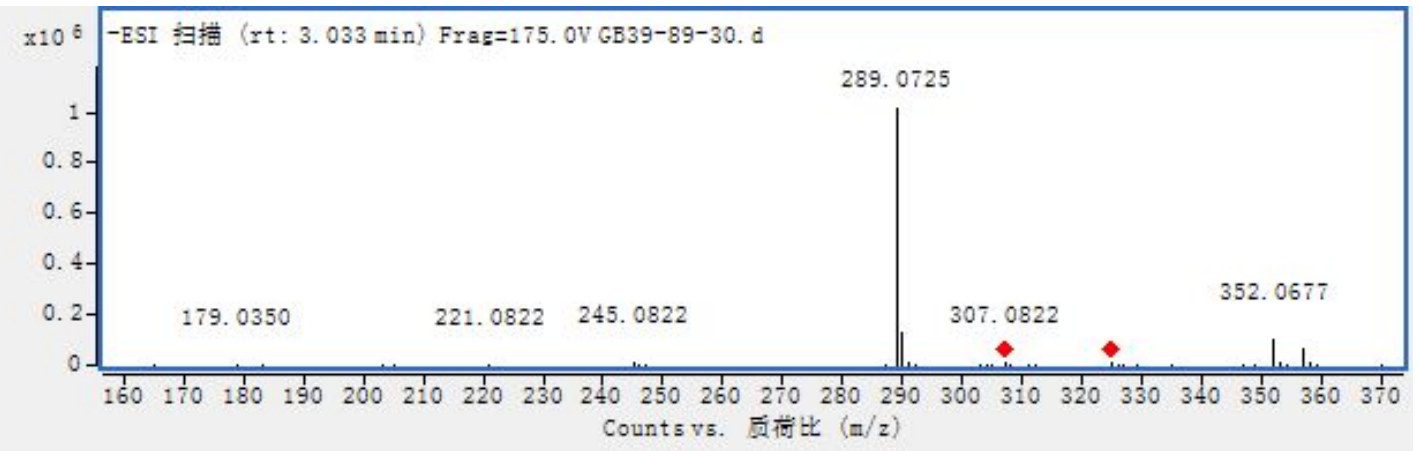

Figure Supporting 19. HR-ESI-MS spectrum of 3.

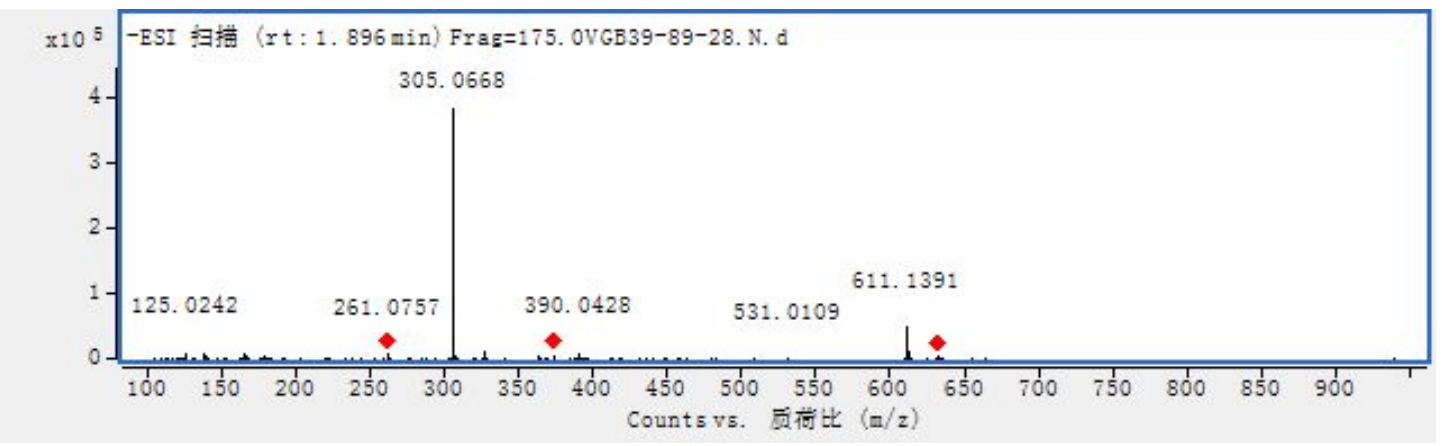

Figure Supporting 20. HR-ESI-MS spectrum of 4. 


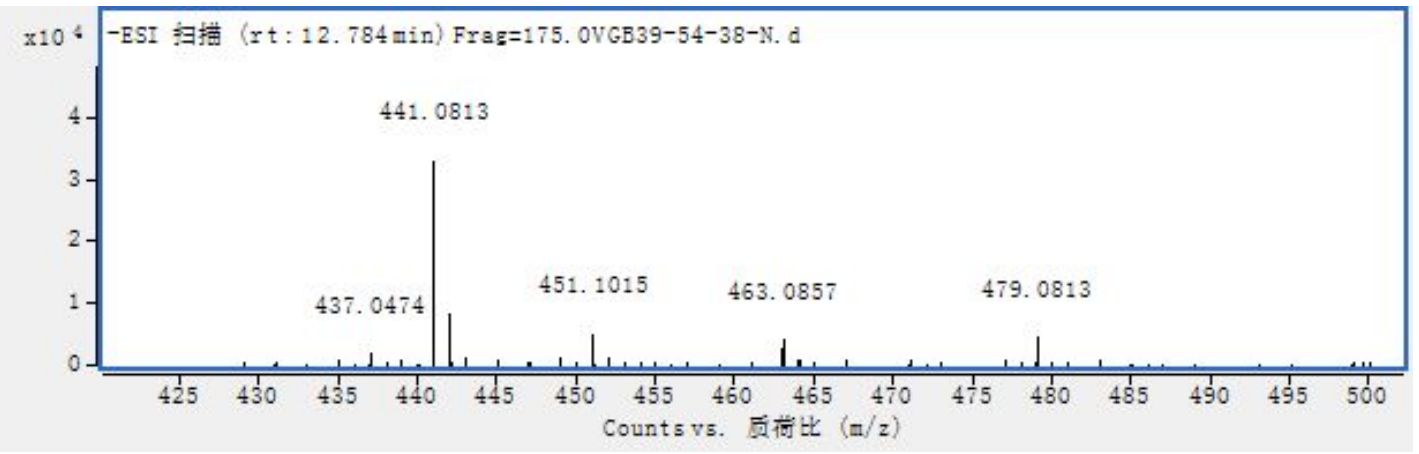

Figure Supporting 21. HR-ESI-MS spectrum of 5.

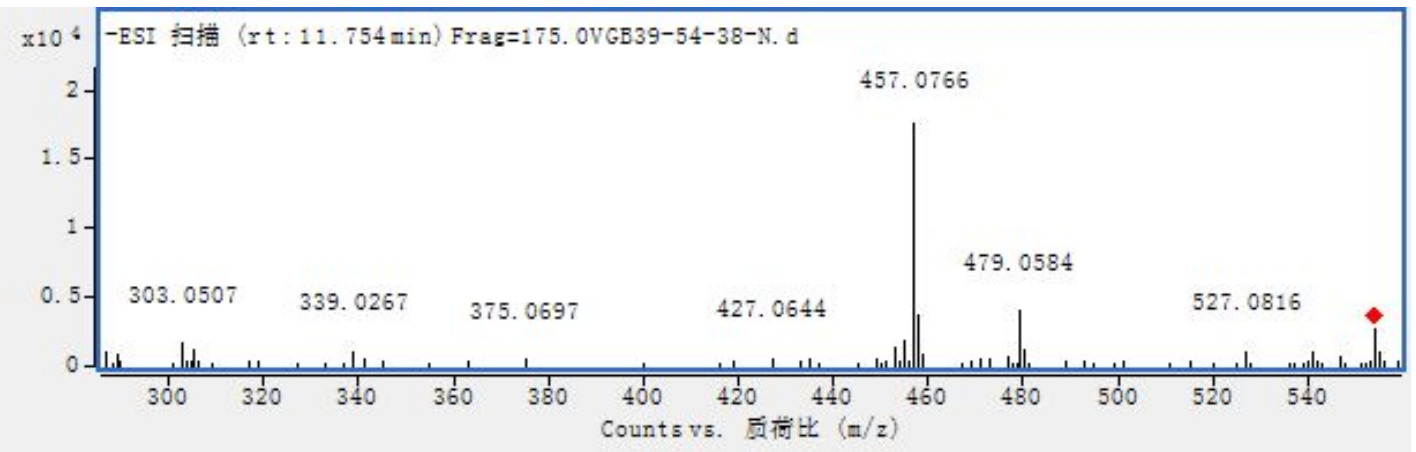

Figure Supporting 22. HR-ESI-MS spectrum of 6.

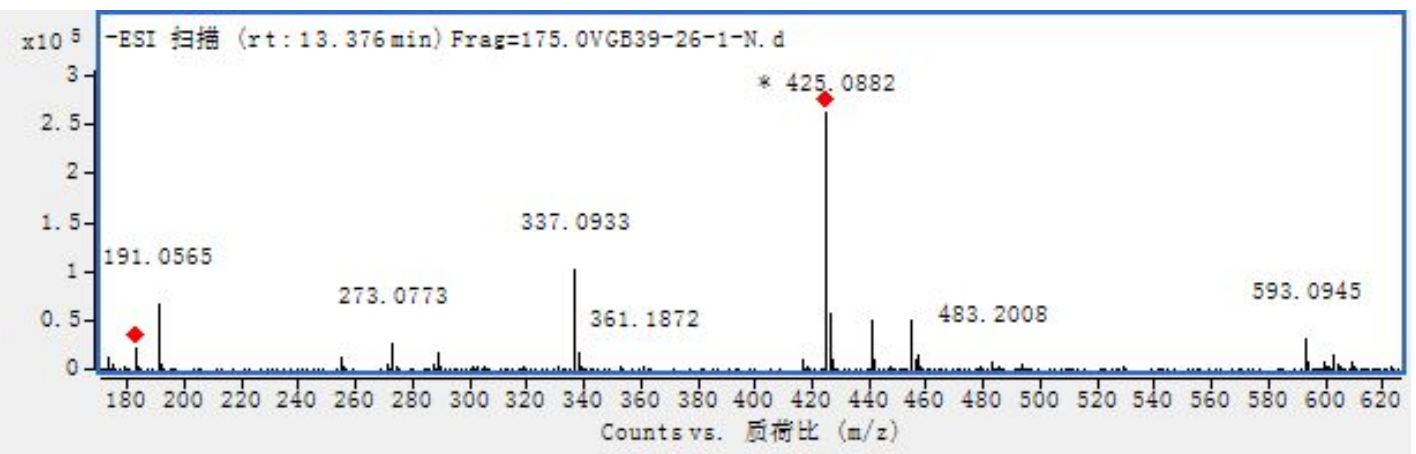

Figure Supporting 23. HR-ESI-MS spectrum of 7.

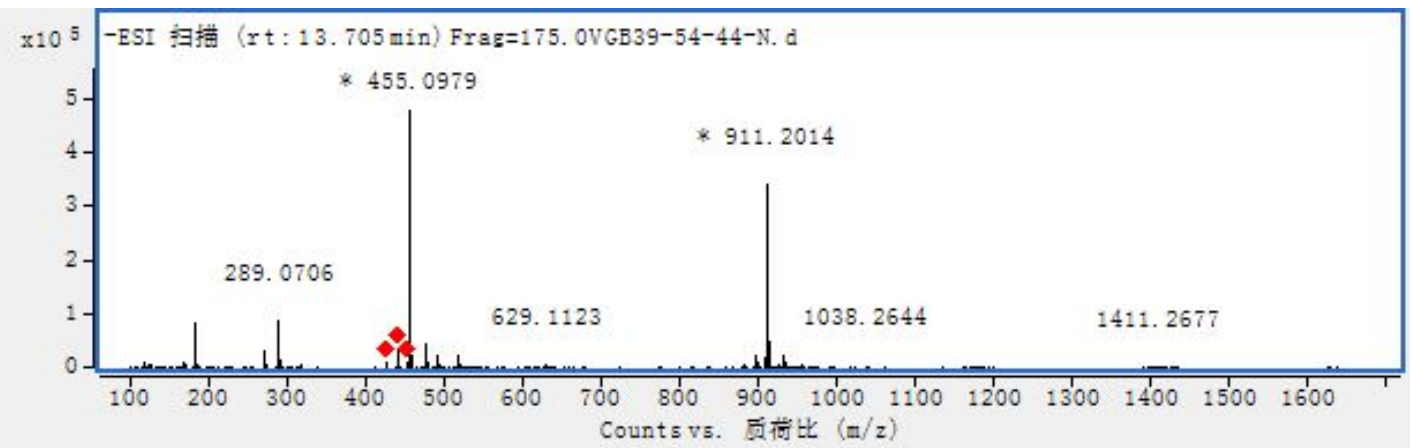

Figure Supporting 24. HR-ESI-MS spectrum of 8. 


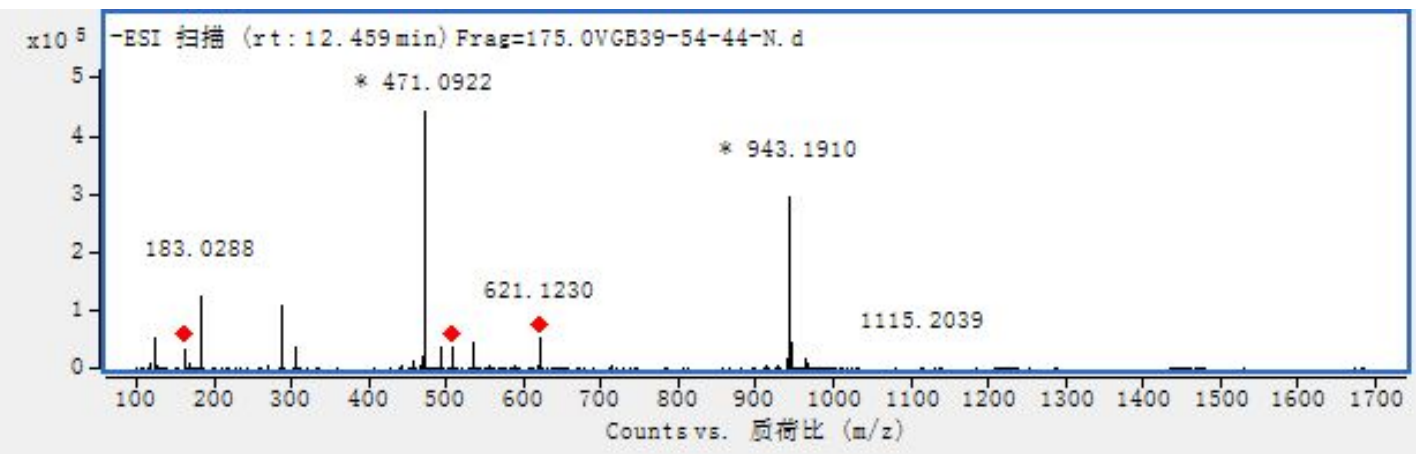

Figure Supporting 25. HR-ESI-MS spectrum of 9.

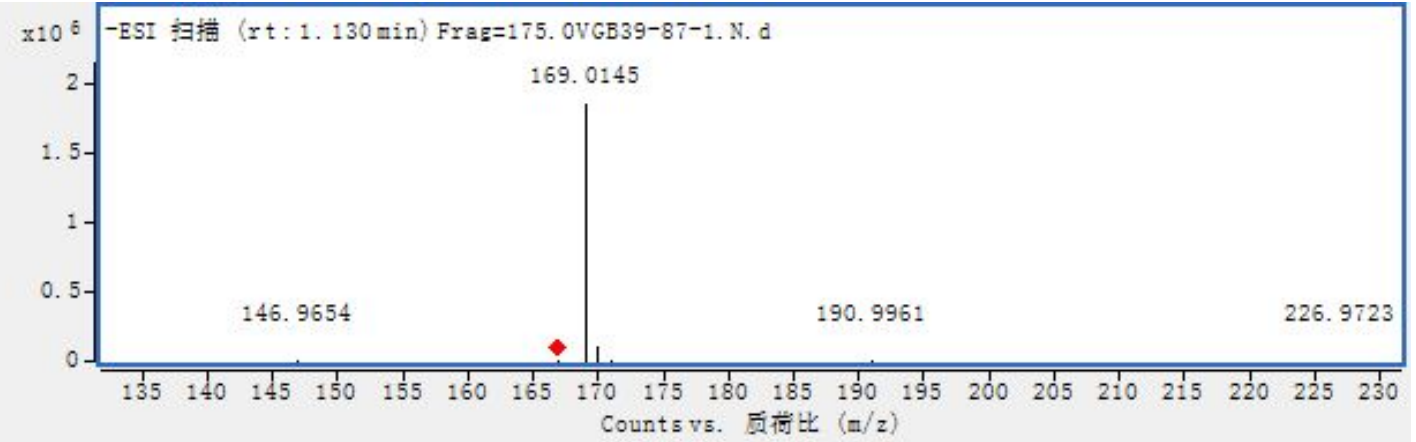

Figure Supporting 26. HR-ESI-MS spectrum of 10.

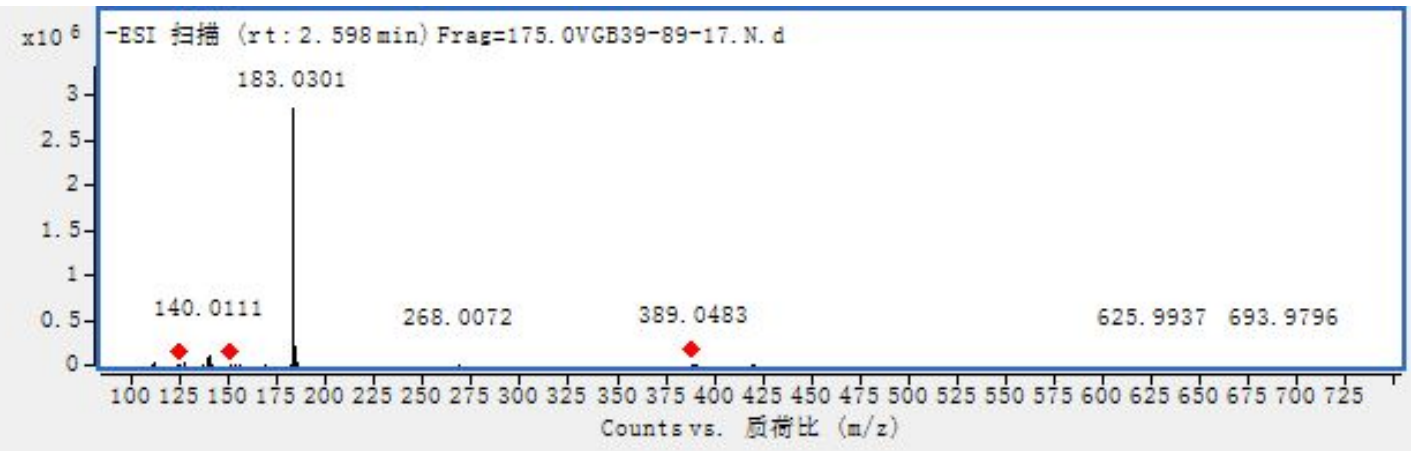

Figure Supporting 27. HR-ESI-MS spectrum of 11.

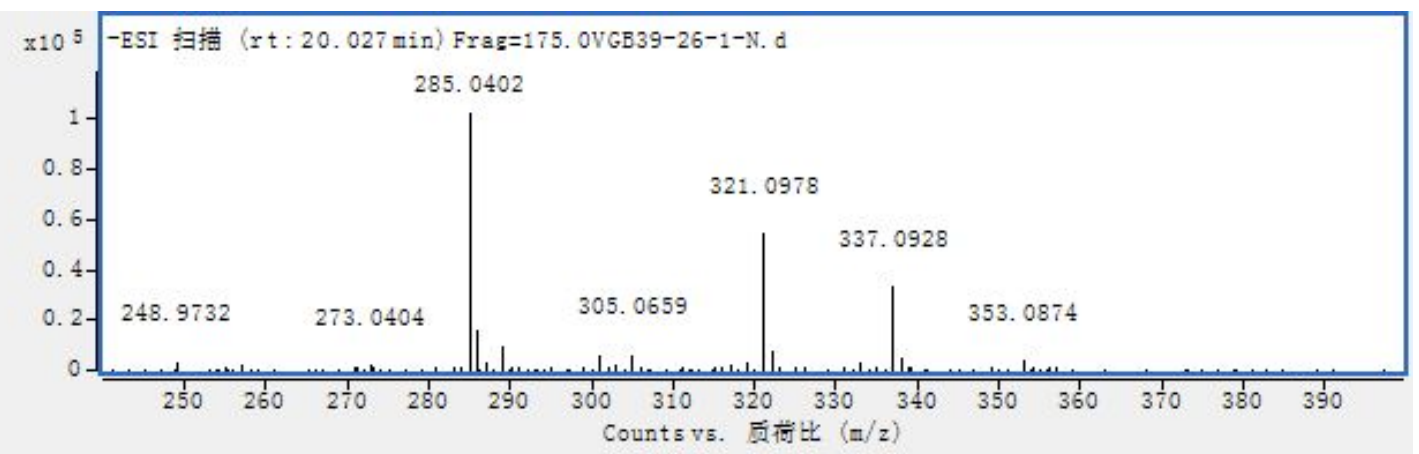

Figure Supporting 28. HR-ESI-MS spectrum of 12. 


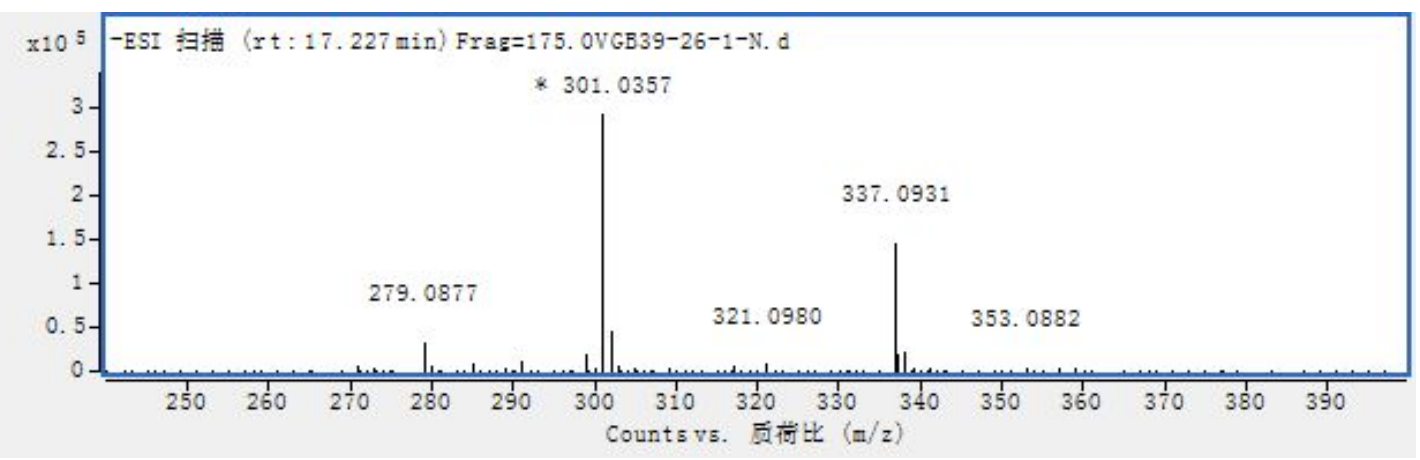

Figure Supporting 29. HR-ESI-MS spectrum of 13.

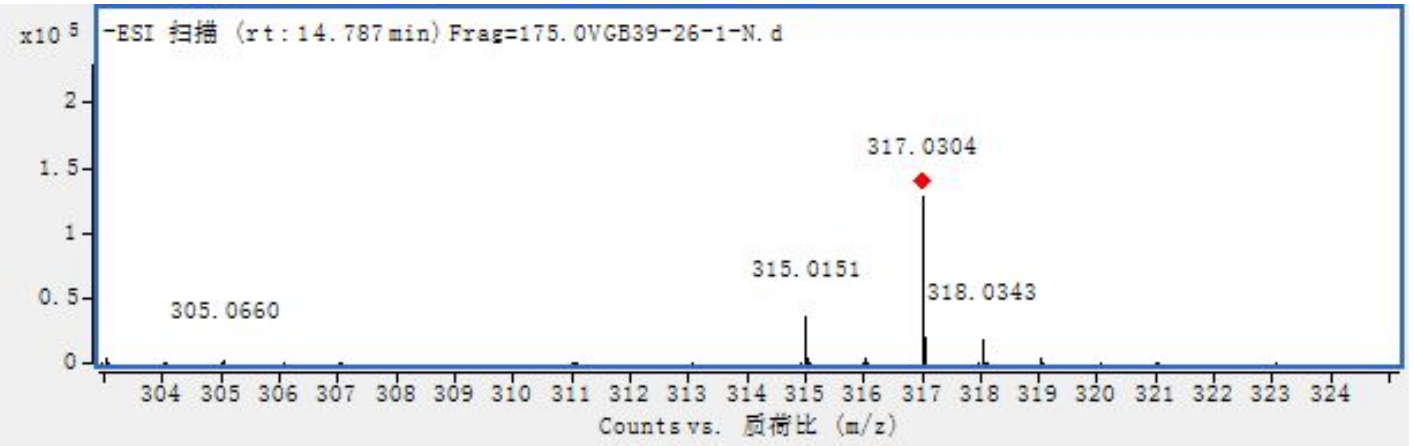

Figure Supporting 30. HR-ESI-MS spectrum of 14.

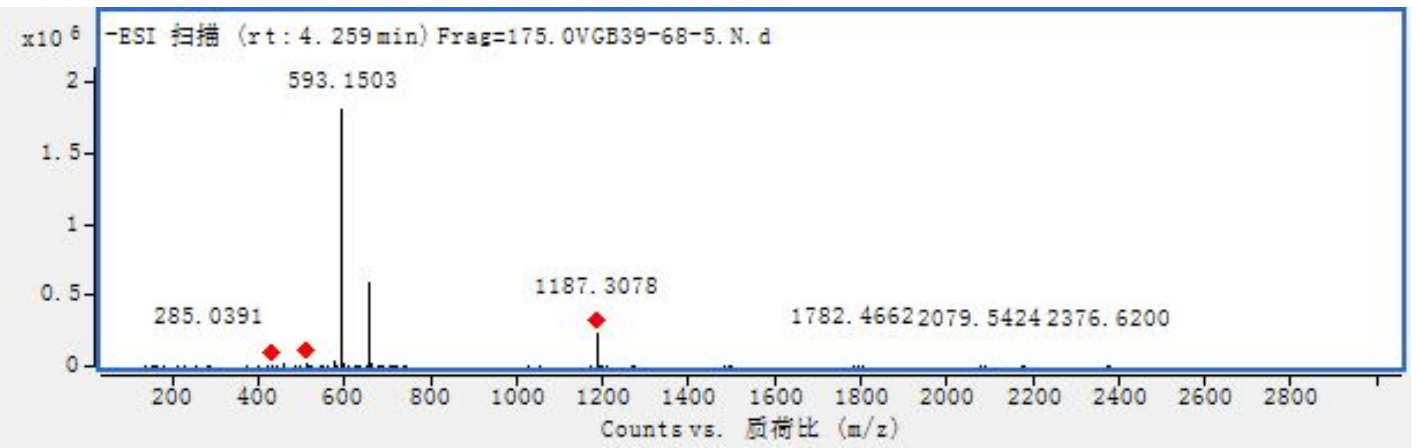

Figure Supporting 31. HR-ESI-MS spectrum of 15.

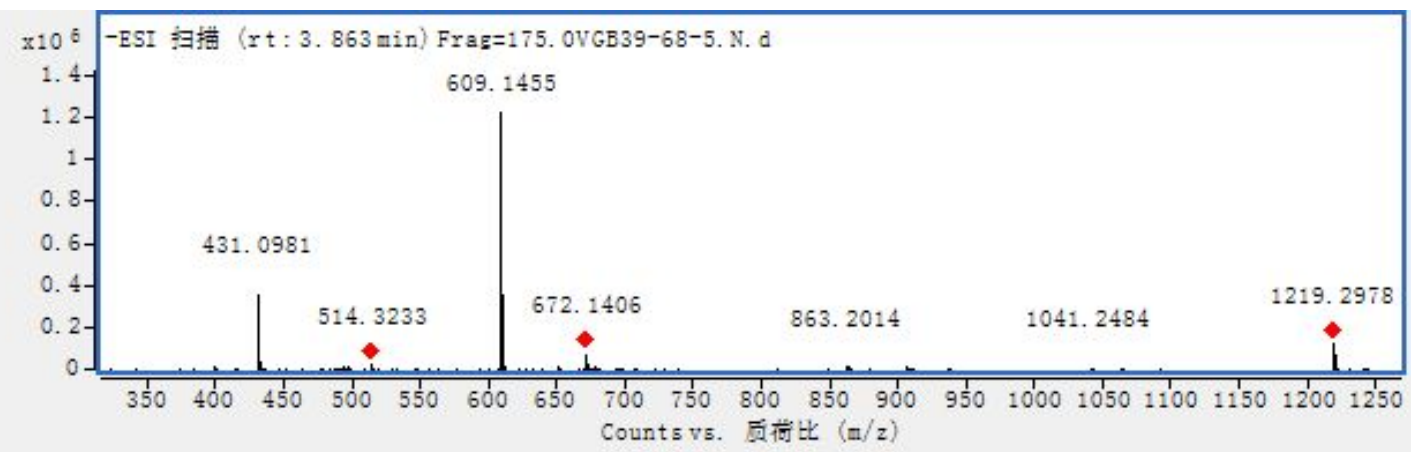

Figure Supporting 32. HR-ESI-MS spectrum of 16. 


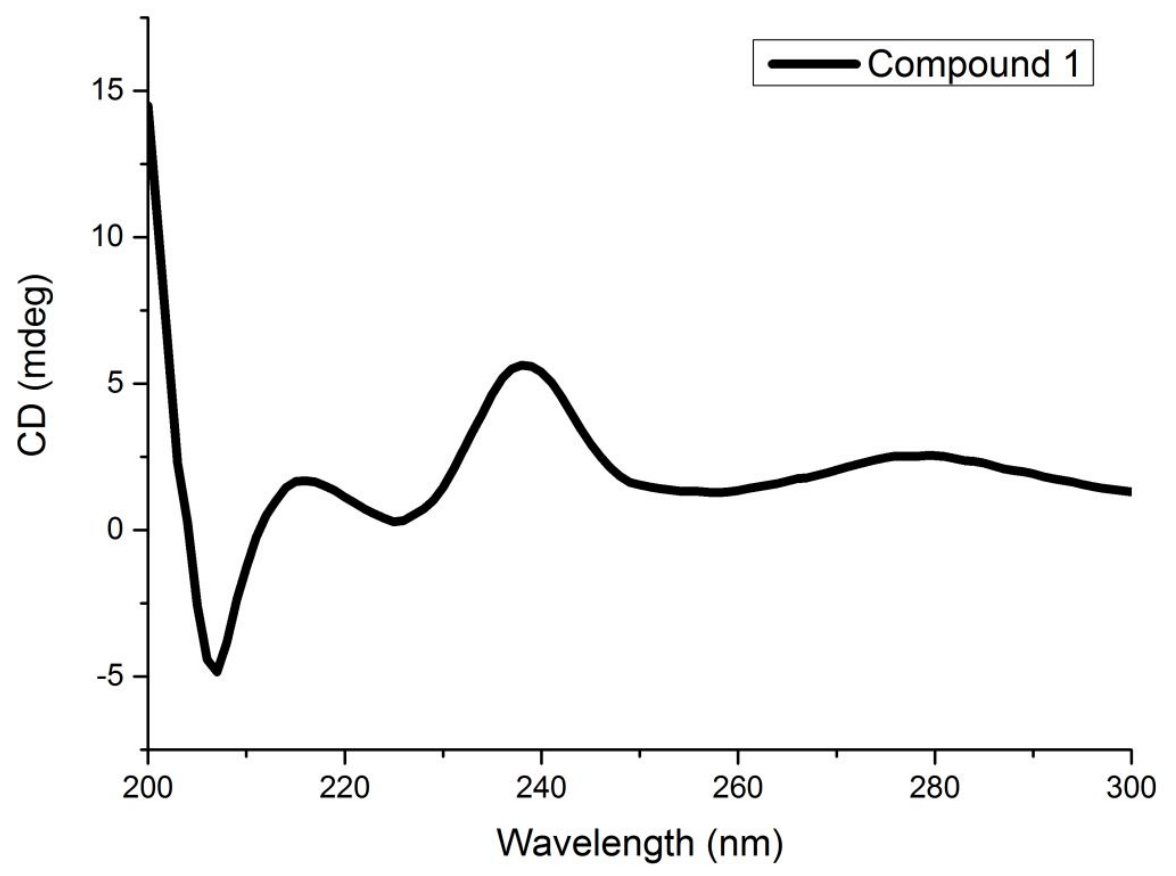

Figure Supporting 33. Circular dichroism spectra of compound 1.

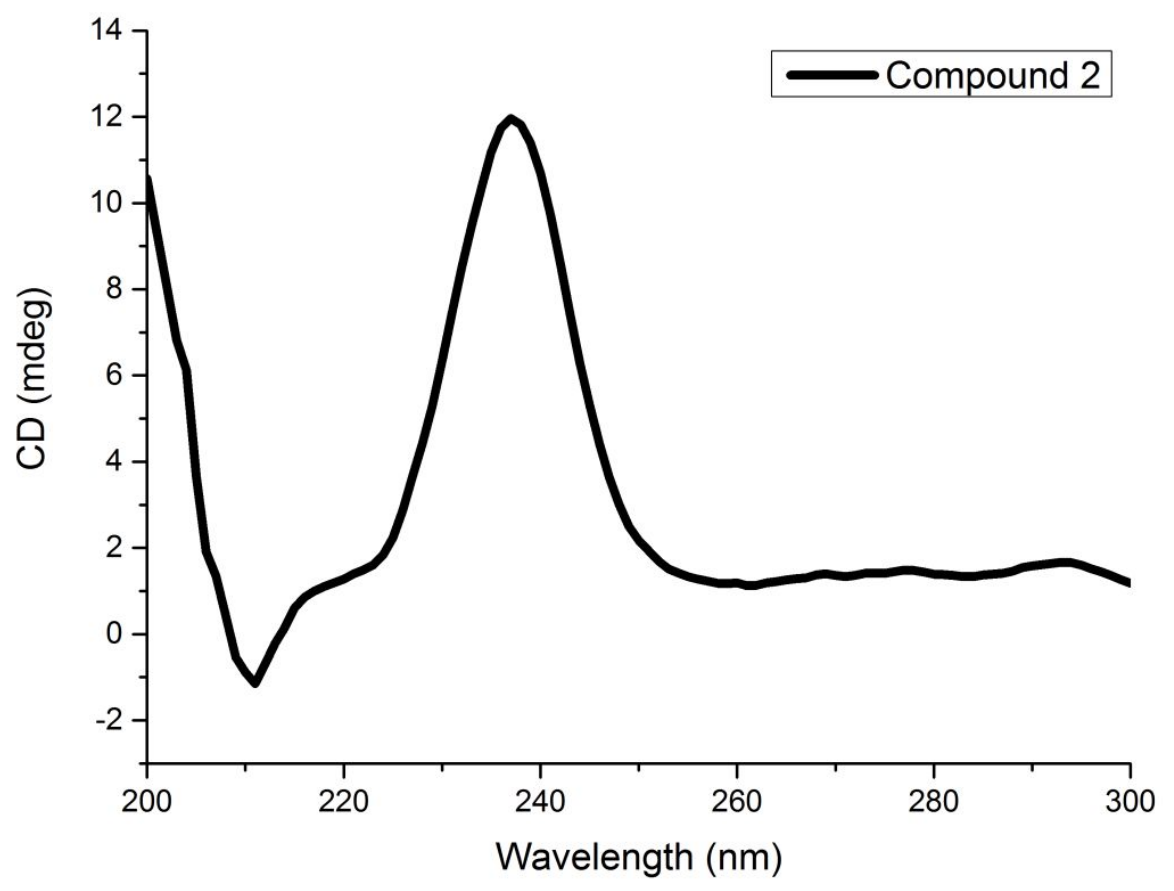

Figure Supporting 34. Circular dichroism spectra of compound 2. 

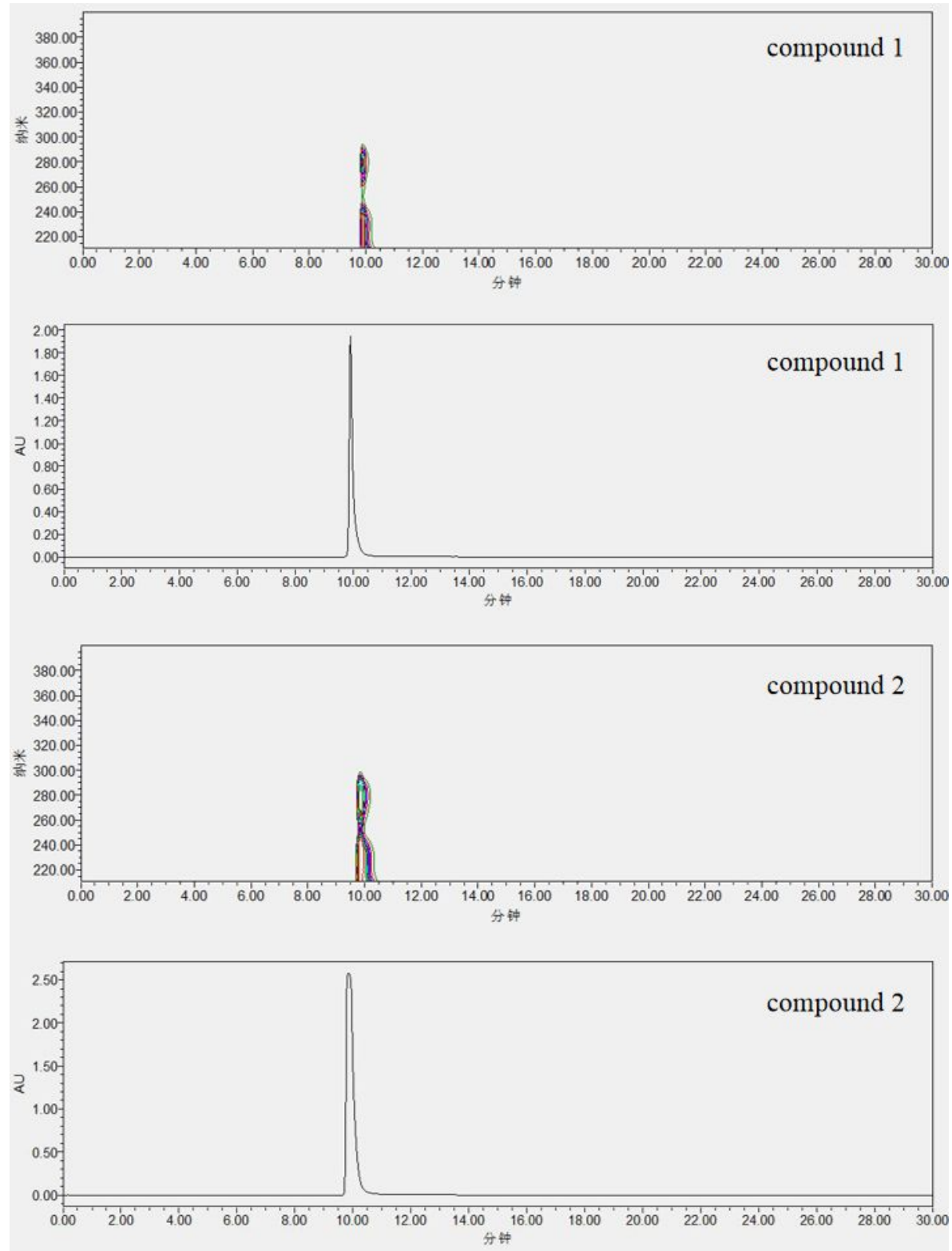

Figure Supporting 35. Purity checks of $\mathbf{1}$ and $\mathbf{2}$ by HPLC with a chiral column. 


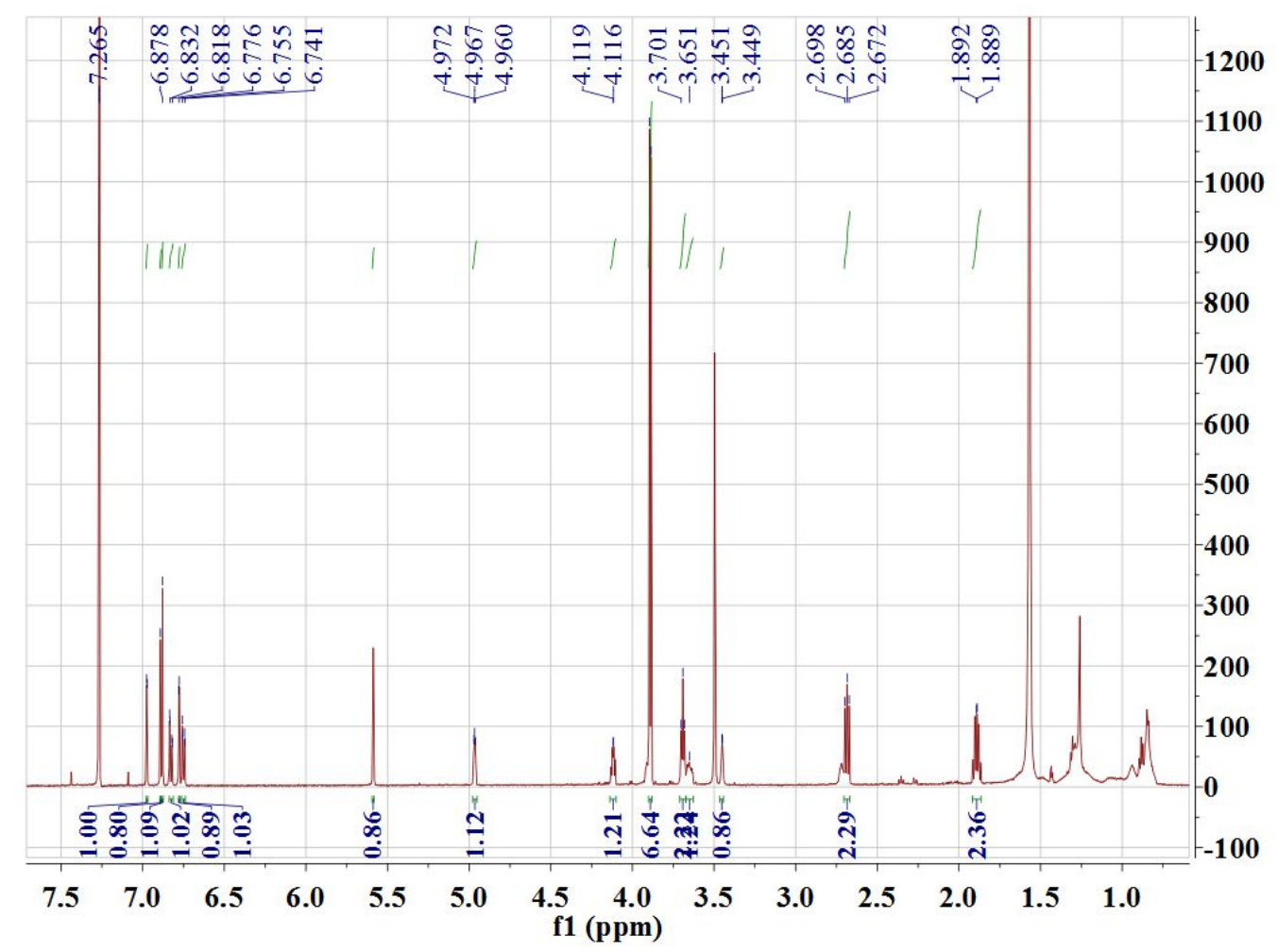

Figure Supporting 36. ${ }^{1} \mathrm{H}$ NMR data of compound $\mathbf{1 a}$ in $\mathrm{CDCl}_{3}-d$.

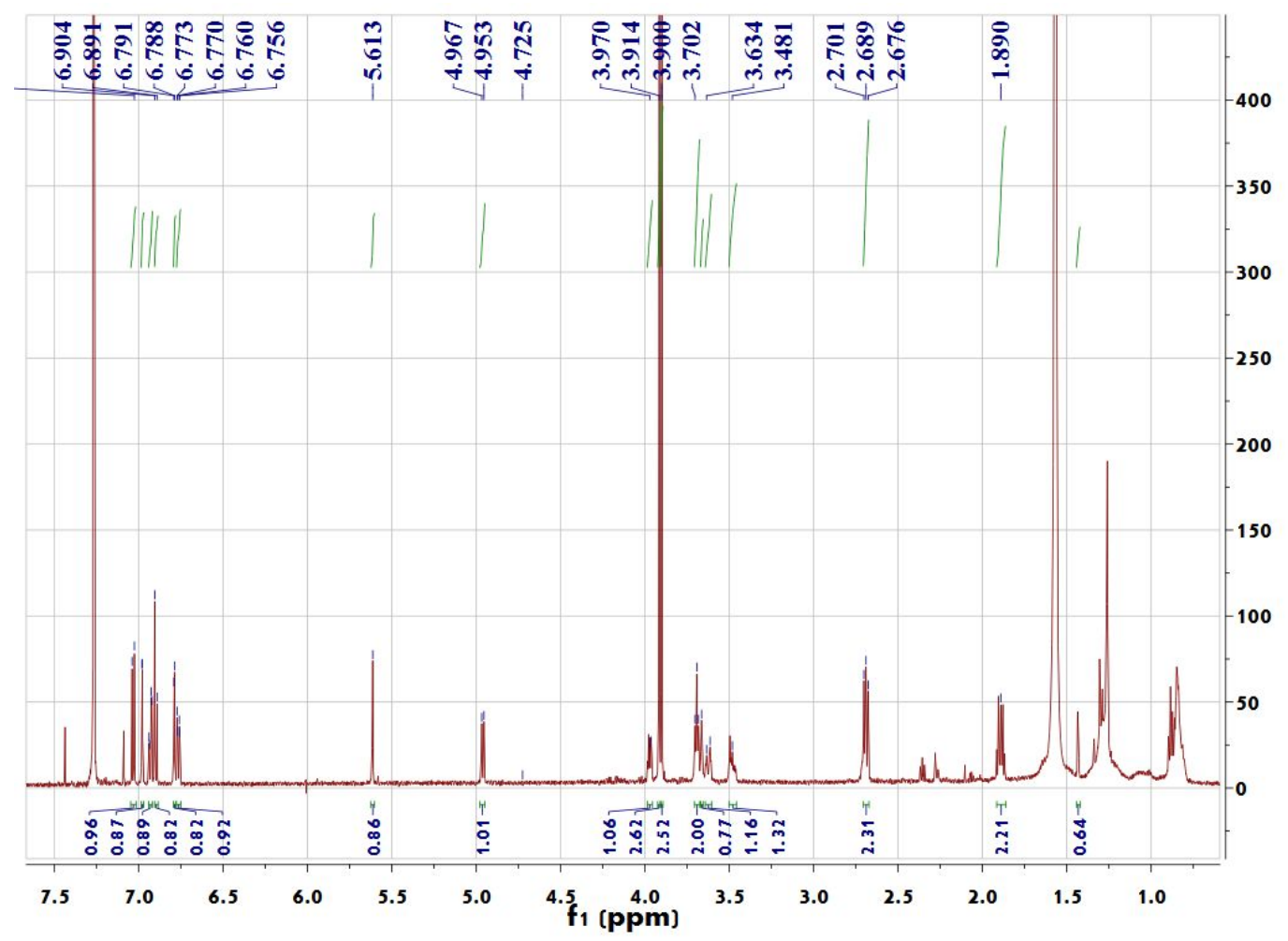

Figure Supporting 37. ${ }^{1} \mathrm{H} \mathrm{NMR}$ data of compound 2a in $\mathrm{CDCl}_{3}-d$. 


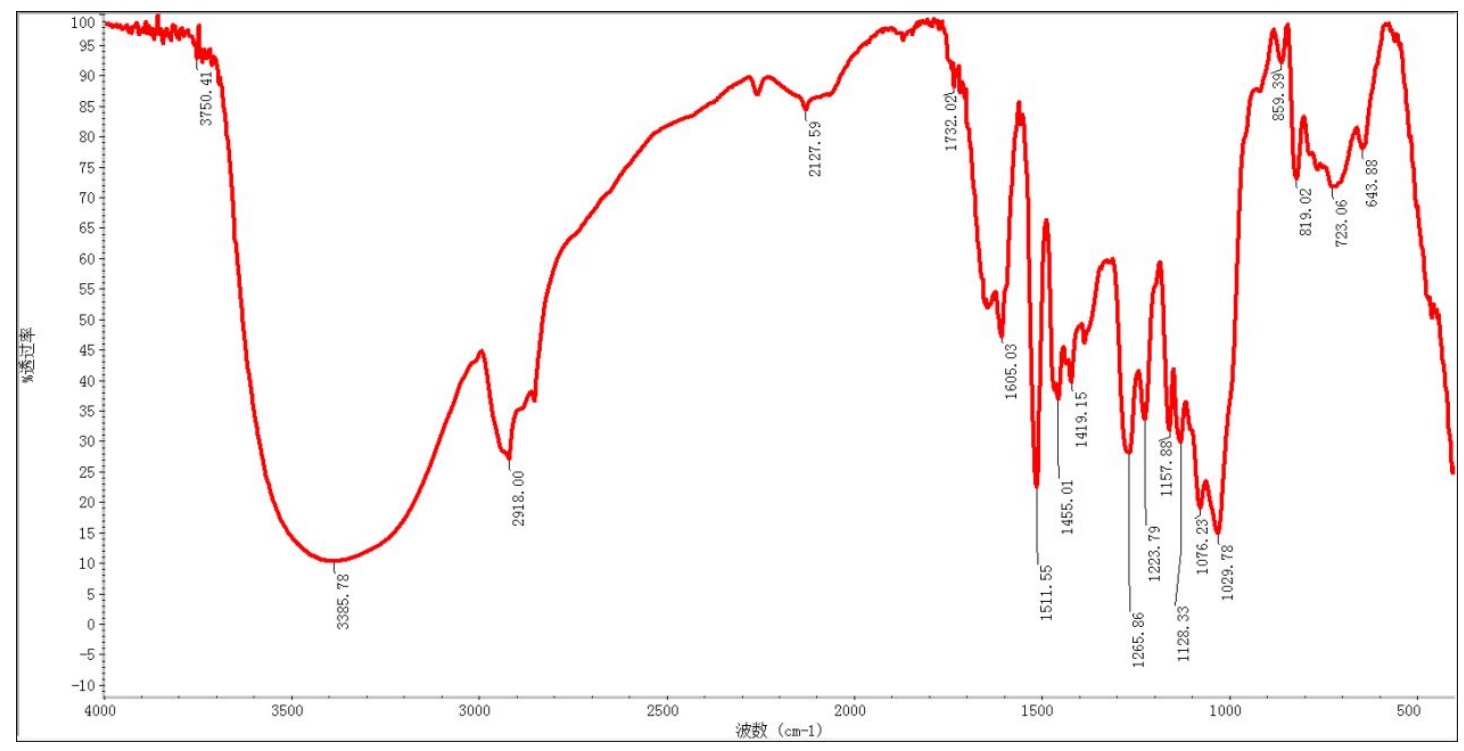

Figure Supporting 38. The IR spectrum of compound 1.

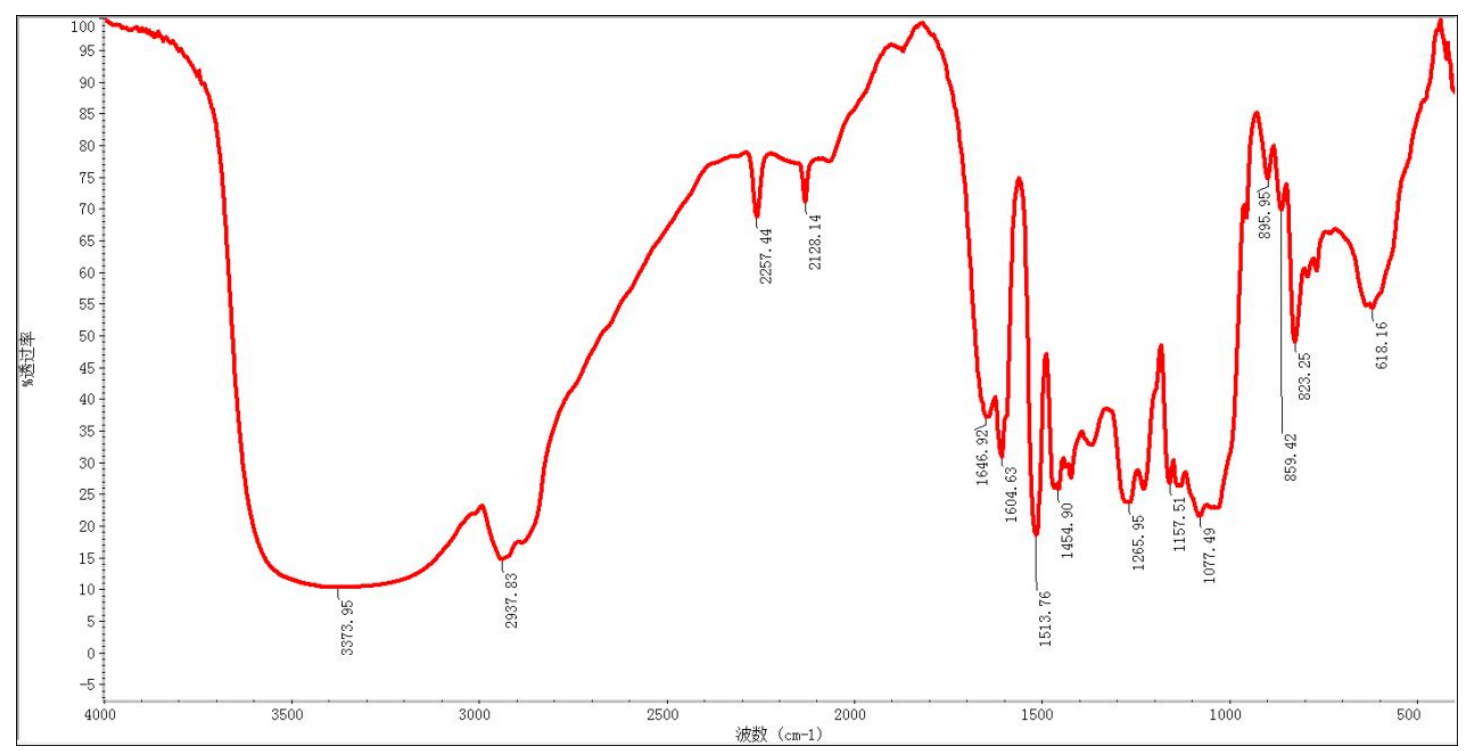

Figure Supporting 39. The IR spectrum of compound 2.

Acid Hydrolysis and Sugar Analysis of Compound 1. The method was modified according to reference with some modification. ${ }^{l}$ Briefly, compound $\mathbf{1}(0.5 \mathrm{mg})$ was melted in $2 \mathrm{M} \mathrm{HCl}(0.8 \mathrm{~mL})$, and heated in water bath for $4 \mathrm{~h}$ at $80{ }^{\circ} \mathrm{C}$. The reactants were extracted using chloroform to get the supernatant and vacuum freeze-dried. The sample was melted in $2 \mathrm{~mL}$ of pyridine mixed with $22 \mathrm{mg} / \mathrm{mL}$ L-cysteine methyl ester hydrochloride at $60{ }^{\circ} \mathrm{C}$ for $2 \mathrm{~h}$. The solution was then dried by vacuum freeze-drying, 
following with the addition of $0.2 \mathrm{~mL}$ trimethylsilylimidazole to the solid. The mixture was then heated for $1.5 \mathrm{~h}$ at $70{ }^{\circ} \mathrm{C}$, and then partitioned between $\mathrm{n}$-hexane and water. GC-MS was carried out to analyze the n-hexane fraction with injector temperature at $280{ }^{\circ} \mathrm{C}$. The oven temperature firstly started at $160{ }^{\circ} \mathrm{C}$ for $1 \mathrm{~min}$, and then rose up to $200{ }^{\circ} \mathrm{C}$ at a speed of $6{ }^{\circ} \mathrm{C} / \mathrm{min}$, and then kept warming-up until a temperature of $280{ }^{\circ} \mathrm{C}$ at a speed of $3{ }^{\circ} \mathrm{C} / \mathrm{min}$ and held for $5 \mathrm{~min}$. The glucose standard $(0.3 \mathrm{mg})$ was analyzed under the same condition. A comparison between the sugar standard and the sugar units of compound $\mathbf{1}$ was made with peak and retention time (RT). As a result, D-glucose (RT $22.23 \mathrm{~min}$ ) was confirmed in compound $\mathbf{1}$.

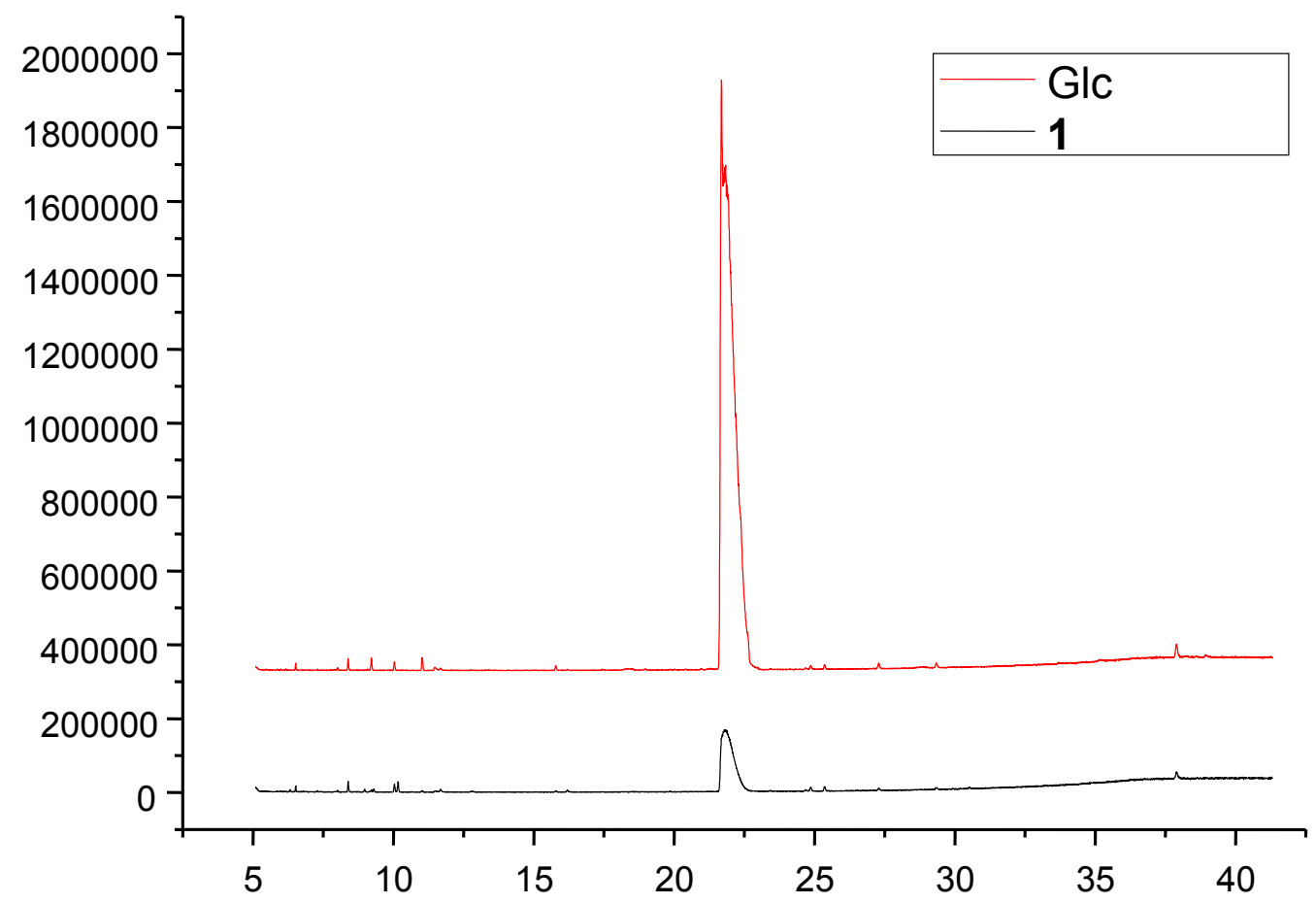

Figure Supporting 40. GC-MS identification of the glucose moiety in compound 1. 


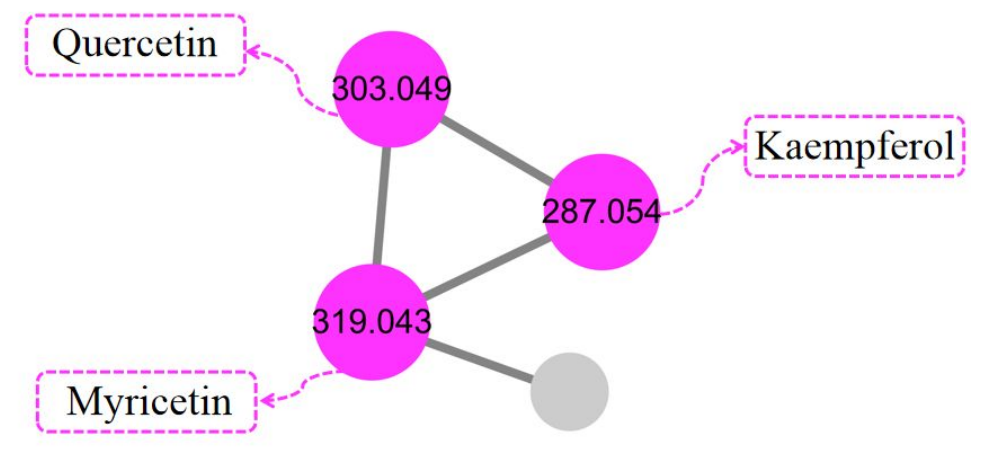

Figure Supporting 41. Molecular networking of flavonols in Huangjinya green tea.

Table Supporting 1. HPLC preparation method for compound 1 and 2 .

\begin{tabular}{llll}
\hline Time & Flow $(\mathrm{ml} / \mathrm{min})$ & $\mathrm{A} \%$ (water) & $\mathrm{B} \%$ (acetonitrile) \\
\hline 0 & 2 & 87 & 13 \\
35 & 2 & 87 & 13 \\
36 & 2 & 70 & 30 \\
38 & 2 & 70 & 30 \\
39 & 2 & 87 & 13 \\
45 & 2 & 87 & 13 \\
\hline
\end{tabular}

Table Supporting 2. The inhibitory activities of the compounds against AChE in vitro .

\begin{tabular}{cc}
\hline Compounds & $\mathrm{IC}_{50}(\mu \mathrm{M})$ \\
\hline $\mathbf{1}$ & $0.75 \pm 0.04$ \\
$\mathbf{2}$ & $0.19 \pm 0.02$ \\
Huperzine-A & $0.29 \pm 0.05$ \\
\hline
\end{tabular}

